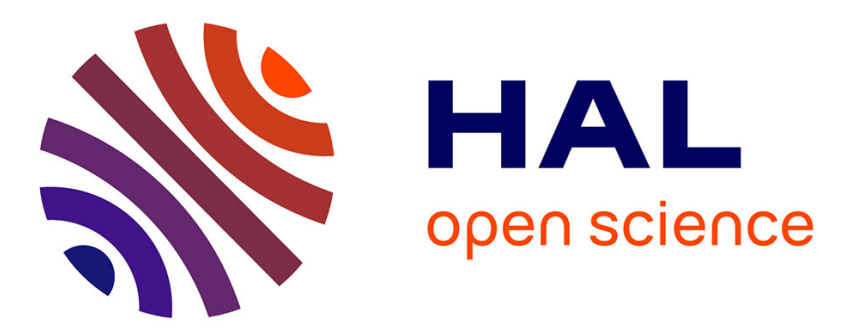

\title{
Kinetics of high temperature oxidation of chromium rich HfC reinforced cobalt based alloys
}

\author{
Elodie Conrath, Patrice Berthod
}

\section{To cite this version:}

Elodie Conrath, Patrice Berthod. Kinetics of high temperature oxidation of chromium rich HfC reinforced cobalt based alloys. Corrosion Engineering, Science and Technology, 2014, 49 (1), pp.45-54. 10.1179/1743278213Y.0000000105 . hal-02541582

\section{HAL Id: hal-02541582 \\ https://hal.science/hal-02541582}

Submitted on 14 Apr 2020

HAL is a multi-disciplinary open access archive for the deposit and dissemination of scientific research documents, whether they are published or not. The documents may come from teaching and research institutions in France or abroad, or from public or private research centers.
L'archive ouverte pluridisciplinaire HAL, est destinée au dépôt et à la diffusion de documents scientifiques de niveau recherche, publiés ou non, émanant des établissements d'enseignement et de recherche français ou étrangers, des laboratoires publics ou privés. 


\title{
Kinetics of high temperature oxidation of chromium-rich HfC-reinforced cobalt-based alloys
}

\author{
Elodie Conrath, Patrice Berthod \\ Institut Jean Lamour (UMR CNRS 7198) \\ Department Chemistry and Physics of Solids and Surfaces \\ Team "Surface and Interfaces, chemical reactivity of materials" \\ Faculty of Sciences and Technologies, Boulevard des Aiguillettes, B.P. 70239, 54506 \\ Vandoeuvre-lès-Nancy, France
}

Elodie Conrath's contact details:

Phone: (+33)383684699, Fax; (+33)383684611, E-mail: elodie.conrath@univ-lorraine.fr

Patrice Berthod's contact details (corresponding author):

Phone: (+33)383684666, Fax; (+33)383684611, E-mail: pberthodcentralelille1987@orange.fr

Postprint version of Corrosion Engineering, Science and Technology 2014 Vol 49 №1 45-54.

DOI 10.1179/1743278213Y.0000000105

\begin{abstract}
:
Mostly known to improve the high temperature oxidation resistance of superalloys hafnium may also form carbides. Several percents of $\mathrm{Hf}$ allow developing a dense carbide network to mechanically strengthen alloys. Here the high temperature oxidation behaviour of three $\mathrm{HfC}$-containing cobalt alloys was characterized at all steps of a thermogravimetry test: heating, isothermal stage and cooling, with comparison with two Co-Cr-C model alloys. The five alloys were heated in synthetic air, maintained at $1200^{\circ} \mathrm{C}$ during 50 hours, then cooled. The mass gains were plotted versus time or according to $\{\mathrm{m} \times \mathrm{dm} / \mathrm{dt}=\mathrm{Kp}-\mathrm{m} \times \mathrm{Kv}\}$ to specify the isothermal kinetic constants, or versus temperature to determine how oxidation acts during heating and oxide spallation occurs during cooling. Compared to the ternary alloys the oxidation of the HfC-reinforced alloys starts earlier but leads to lower mass gains during heating, the isothermal oxidation is faster and oxide spallation occurs later.
\end{abstract}

Keywords: Cobalt-based alloys; Hafnium carbides; Isothermal oxidation; Oxidation at heating; Oxide spallation at cooling; Oxide characterization 


\section{Introduction:}

Many metallic pieces working at very high temperature must be fabricated by classical foundry because of the necessity 'to achieve coarse grains for maximizing creep-resistance (Ref. 1)' and of a too compact shape not compatible with directional solidification. Then, such hot pieces cannot be manufactured as single-crystals (which belong to the most efficient superalloys) and their constitutive alloys necessarily present multiple randomly oriented grain boundaries. These ones, which are the weakest zones in the alloys when used under stresses at temperatures higher than the equi-cohesive temperature, must be reinforced by hard particles. Such particles can be eutectic carbides appearing in the interdendritic spaces at the end of solidification. This is the case of the acicular chromium carbides or script-like tantalum carbides which are often 'observed in cast cobalt-based superalloys (Ref. 2)' containing several tenths of weight percents of carbon. The carbides reinforcing grain boundaries must be extremely stable at high temperature when the alloys are considered for especially severe thermal applications. They must be notably much more stable than chromium carbides, the volume fractions of which rapidly decrease at high temperature, and even than the tantalum carbides 'which get fragmented (Ref. 3)' and then lead to 'significant loss of thermo-mechanical properties (Refs. 4-6)' and even 'changes in high temperature oxidation behaviour (Ref. 7)'. These evolutions necessarily affect sooner or later the interdendritric carbides reinforcing the concerned equi-axed superalloys but, fortunately, there exist carbides particularly resistant to such morphological phenomena. This is notably the case of the HfC carbides which were 'recently obtained in solidified cobalt-based alloys (Ref. 8)' with the shape of script-like carbides forming an interdendritic eutectic compound with matrix as the more common tantalum carbides.

Hafnium is the most often considered as an element able to significantly improve the behavior of refractory alloys and superalloys in high temperature oxidation, for example by lowering the oxide growth rate and by enhancing the adherence of the protective oxides on the alloys (Refs. 9-10). With these objectives $\mathrm{Hf}$ is generally added for example, by targeting near $1 \mathrm{wt}$ \% (typically between 0.25 and $1.5 \mathrm{wt} . \%$ ), to 'commercial alloys (Refs. 11-12), to 'iron- based bulk alloys rich in $\mathrm{Cr}$ and Al (Refs. 13-14)', 'to aluminides (Refs. 15-16)' and to 'TBC-supporting bond coats (Refs. 17-18)', as red in the most recent literature. In contrast it seems that hafnium was much more rarely selected for its ability to form MC carbides destined to enhance mechanical properties.

In the present work three cobalt-based alloys were elaborated by foundry. First, all contain $25 \mathrm{wt} . \% \mathrm{Cr}$ to ensure resistance against oxidation at high temperature. Second, two levels of carbon were considered $(0.25 \mathrm{wt} . \%$ and $0.50 \mathrm{wt} . \%)$ to promote carbides' formation. Third sufficient hafnium was added for having for two alloys as many $\mathrm{Hf}$ atoms as $\mathrm{C}$ atoms, and for the third alloy more $\mathrm{C}$ atoms than $\mathrm{Hf}$ atoms. The objective was to dispose of two alloys with only $\mathrm{HfC}$ as carbides in two different volume fractions, and, for the third one, to obtain two types of carbides simultaneously, $\mathrm{HfC}$ and chromium carbides. In parallel two ternary alloys with the same $\mathrm{Cr}(25 \mathrm{wt} . \%)$ and $\mathrm{C}$ contents $(0.25$ and $0.50 \mathrm{wt} . \%)$ were synthesized following the same elaboration route and parameters, to act as references for comparison. The objectives were to characterize their kinetic and phenomena of oxidation at $1200^{\circ} \mathrm{C}$, typical level of temperature at which it is wished to use later such special alloys. A particular attention was focused on the effect - beneficial or detrimental: to discover - of hafnium, which is known to be active in oxidation at high temperature, when this element is present in alloys with so unusually high contents. 


\section{Experimental methods:}

Synthesis of the alloys and preparation of the samples

For each of the five alloys a total charge of about $40 \mathrm{~g}$ constituted of pure elements (>99.9 wt. $\%$, Alfa Aesar) was prepared by targeting the following chemical compositions (in weight percents):

- $\mathrm{Co}$ (bal.)-25Cr-0.25C-3.72Hf (atomic equality between $\mathrm{C}$ and $\mathrm{Hf}$ ), alloy thereafter named: "CoHfC-1",

- $\mathrm{Co}$ (bal.)-25Cr-0.50C-3.72Hf ( $\mathrm{C}$ atomic content equal to twice the $\mathrm{Hf}$ one), named "CoHfC-2/1",

- $\mathrm{Co}$ (bal.)-25Cr-0.50C-7.44Hf (atomic equality between $\mathrm{C}$ and $\mathrm{Hf}$ again, double $\mathrm{HfC}$ population expected by comparison with the CoHfC-1 alloy), named "CoHfC-2/2",

- Co-(bal.)-25Cr-0.25C (to which the CoHfC-1 alloy will be compared), named "Co-1"

- $\mathrm{Co}$ (bal.)-25Cr-0.50C (to which the CoHfC-2/1 and CoHfC-2/2 alloys will be compared), named "Co-2".

All these alloys were elaborated by foundry using a High Frequency induction furnace (CELES, parameters: $4 \mathrm{kV}, 110 \mathrm{kHz}$ ). The fusion, 3 minutes-dwell and solidification of the alloys were performed in the water-cooled copper crucible of the furnace, with a surrounding inert atmosphere of pure argon (300 mbars at room temperature) isolated from the laboratory air with a silica tube chamber. The obtained compact ingots were cut to obtain the different parts necessary for the study: the parts prepared to be used for the as-cast microstructure characterization, and the parts destined to the oxidation tests in thermo-balance.

\section{High temperature oxidation tests and kinetic exploitations}

The parts destined to oxidation test were cut by respecting specific shapes and dimensions (parallelepipeds of about $8 \times 8 \times 3 \mathrm{~mm}^{3}$ ). They were thereafter polished, by using 240-grit $\mathrm{SiC}$ papers to smooth edges and corners, and thereafter polished all around with 1200-grit $\mathrm{SiC}$ papers, with special attention to the two main planar faces and the four planar sides.

A sample of each of the five alloys was subjected to high temperature oxidation in a SETARAM TGA92 thermo-balance TGA in a constant flow of synthetic air $\left(80 \% \mathrm{~N}_{2}-20 \%\right.$ $\mathrm{O}_{2}$ ). In each case, after a heating at $+20^{\circ} \mathrm{C} \mathrm{min}^{-1}$, the sample was maintained at $1200^{\circ} \mathrm{C}$ during a 50 hours-long dwell, then cooled at $-5^{\circ} \mathrm{C} \mathrm{min}{ }^{-1}$, rate supposed to be low enough to hope preserving from spallation the oxide scale developed all over the sample.

The mass gain files (record step: about 40s) were thereafter treated with the Excel software. It was first verified, by plotting versus time the mass gain recorded during the $1200^{\circ} \mathrm{C}$-stage, that the isothermal oxidation kinetic was of the parabolic type and then seemingly follow the Wagner's law. This parabolic regime may be preceded by a short linear transient oxidation at the beginning, the linear constant of which, $\mathrm{Kl}$, was then first determined. The isothermal mass gain were first conventionally exploited to specify the parabolic constant $\mathrm{Kp}$, by plotting 
them versus the square root of time and by considering the average slope of the obtained more or less linear curve.

Since the studied alloy possibly presents a chromia-forming behaviour, a minimization of the oxidation rate when assessed from mass gain results may occur because of the possible mass loss by chromia volatilization. Indeed, $\mathrm{Cr}_{2} \mathrm{O}_{3}$ in air at more than $1000^{\circ} \mathrm{C}$ tends to be oxidized again in volatile $\mathrm{CrO}_{3}$. The higher the temperature the faster this phenomenon. For $1200^{\circ} \mathrm{C}$ chromia volatilization must be seriously taken into account, with the determination of the chromia volatilization constant $\mathrm{Kv}$ together with $\mathrm{Kp}$. For that the previous first $\mathrm{Kp}$ calculation was systematically doubled with a Kp-Kv assessment using a 'method recently developed (Ref. 19)': plotting the product $\{\mathrm{m} \times \mathrm{dm} / \mathrm{dt}\}$ (the mass gain per surface unit area multiplied by the same quantity but derived by regard to time) versus $\{-\mathrm{m}\}$ (opposite of the mass gain per surface unit area). As it was demonstrated in 'Ref. 19', after a first transient part, the $\{m \times d m / d t\}$ plotted versus $\{-m\}$ becomes linear, the equation of this straight line being $\{\mathrm{m} \times \mathrm{dm} / \mathrm{dt}=\mathrm{Kp}-\mathrm{m} \times \mathrm{Kv}\}$ : the parabolic constant $\mathrm{Kp}$ and the chromia volatilization constant Kv can be easily deduced as, respectively, the ordinate at the origin and the slope of the straight line.

Before the classical $\mathrm{Kp}$ determination as well as the assessment of the $\{\mathrm{Kp}, \mathrm{Kv}\}$ couple of kinetic constants, the mass gain during the heating (performed in presence of synthetic air) needed to be itself determined. Indeed this first mass gain is to be known and added to the eventual linear mass gain to allow an accurate determination of $\mathrm{Kp}$ (or $\mathrm{Kp}-\mathrm{Kv}$ ) since the oxide thickness initially existing influences the parabolic regime. Since the used thermobalance was not a symmetric one, the effect of air buoyancy was analyzed and the mass gain at heating (and also at cooling) was corrected using a 'method already described in an earlier work (Ref. 20)'. For that the mass gains were plotted versus temperature instead of time, and corrected from the apparent mass variations due to the buoyancy variations of the heated air. The corrected curves of mass gain versus temperature during the heating allow specifying first the temperature at which the mass gain really due to oxidation becomes to be detectable by the used thermo-balance. This is of course a criterion which closely depends on the used thermo-balance and not an absolute criterion. However the comparison of these "oxidation start" temperatures between the different alloys oxidized in the same thermobalance and for the same oxidizing atmosphere and heating rate, may be of great interest.

The cooling parts of these curves of mass gain plotted versus temperature and corrected from the air buoyancy variations were themselves exploited to specify the temperatures at which oxide spallation occurs during the cooling, as 'earlier done in (Ref. 21)'.

\section{Metallography characterization}

The parts destined to the observations of the as-cast microstructures were embedded in a cold mixture composed of a liquid resin (DBF from ESCIL, $82 \%$ in mass) and a hardener (HY956 from ESCIL, 18\%). They were thereafter polished, using first SiC papers with grades from 120 or 240 up to 1200 under water, and second, after intermediate ultra-sonic cleaning, a textile disk enriched with diamond particles (ESCIL) to obtain a mirror-like surface state. 
After the thermogravimetric runs the oxidized samples were first subjected to X-ray diffraction analysis (Philips X'Pert Pro diffractometer) to identify the oxides formed on surface. Second they were coated with a fine gold layer to give electric conductivity to their surface (despite the presence of external oxide scales). This was done to allow thereafter an electrolytic deposition of a thick nickel shell destined to protect the oxide scale from rupture and loss during cutting. The gold-covered oxidized samples were cathodically polarized in a warm $\left(50^{\circ} \mathrm{C}\right)$ Watts' bath to allow the deposition of metallic nickel by reduction of the $\mathrm{Ni}^{2+}$ cations under a current density of about $1.6 \mathrm{~A} / \mathrm{dm}^{2}$. After cutting the oxidized samples in two parts, cross-sections were prepared by following the same metallographic preparation details (embedding and polishing) as for the as-cast samples.

After cutting, embedding and polishing, the global chemical composition of each as-cast alloy was controlled using the Energy Dispersive Spectrometry (EDS) device equipping a Scanning Electrons Microscope (SEM, model: JSM 6010 LA from JEOL), under an acceleration voltage of $20 \mathrm{kV}$

The initial microstructures of the as-cast alloys were examined using the SEM, essentially in the Back Scattered Electrons mode (BSE). X-Ray maps were acquired to study the distribution of the four elements $(\mathrm{Co}, \mathrm{Cr}, \mathrm{C}, \mathrm{Hf})$ in the microstructure, allowing clearly identifying the different particles. The oxide scales and the subsurface microstructures were also examined by SEM/BSE and analyzed by pinpoint SEM/EDS measurements.

\section{Results:}

\section{Chemical compositions and initial microstructures of the alloys}

Preliminarily to the oxidation tests the five alloys were controlled by analyzing the embedded and polished samples with the SEM. The SEM/EDS performed on three $\{\times 1000\}$ areas led to the average chemical composition shown in Table 1 with the standard deviation value for each content. It appears that the targeted compositions were effectively obtained.

The as-cast microstructures of the five alloys are illustrated in Fig. 1. Observed with the SEM in BSE mode the three $\mathrm{Hf}$-containing alloys present an interdendritic network of script-like carbides. These ones appear white, this revealing an average atomic number higher than matrix. They are in the CoHfC-2/1 as numerous as in the CoHfC-1 alloy, while they are significantly more present in the CoHfC-2/2 alloy. As revealed by X-Ray maps (example of the CoHfC-2/1 alloy in Fig. 2) as well as X-ray Diffraction (example of the CoHfC-2/1 alloy again in Fig. 3) these white particles are $\mathrm{HfC}$ carbides. In addition to the interdendritic scriptlike $\mathrm{HfC}$ carbides the presence of other types of $\mathrm{HfC}$ carbides, more compact than the first cited ones, must be noticed. These $\mathrm{HfC}$ carbides may have precipitated at the beginning solidification and are then probably to be qualified as pro-eutectic $\mathrm{HfC}$ carbides.

Obviously the apparent volume fraction of $\mathrm{HfC}$ carbides of both types is closely dependent on the $\mathrm{Hf}$ content in the alloy, and not on the carbon content. The CoHfC-2/1 alloy also contains chromium carbides as also shown by the X-ray maps given in Fig. 2.

The two ternary alloys are also composed of matrix and of chromium carbides. These ones are however very rare in the Co-1 alloy but they are more present, clearly in the interdendritic spaces, in the Co-2 one, thanks to the double carbon content in the second alloy. For a given 
carbon content the presence of hafnium obviously leads to much more carbides than in the ternary alloys, this showing that $\mathrm{Hf}$ is a much stronger carbides-forming element. Some pinpoint EDS measurements performed in the matrix showed that hafnium is totally absent in the matrix of the $\mathrm{Hf}$-containing alloys, this indicating that all $\mathrm{Hf}$ atoms have formed $\mathrm{HfC}$.

\section{High temperature oxidation kinetics: general features}

The isothermal part of the mass gain curves obtained for the three $\mathrm{Hf}$-containing alloys are shown together in Fig. 4, with addition of the mass gain curve obtained for one of the two ternary alloys. The kinetic are seemingly parabolic but much faster than the parabolic part of the Co-1 alloy observed before 100,000 seconds, just before its linear oxidation.

The whole thermogravimetry curves, after correction from the air buoyancy variation, are plotted together in Fig. 5 as mass gain versus temperature instead time. One can distinguish different parts of these curves:

- The first heating part (low temperature) during which oxidation acts faster and faster but is still negligible ("Heating 1" part),

- The second heating part (high temperature) along which the mass gain by oxidation, now clearly detected by the thermo-balance, keeps on accelerating,

- The isothermal stage during which the mass gain continues to increase but slower and slower (Wagner's law), this leading to a vertical straight line in this type of graphical representation,

- The first cooling part (high temperature) during which mass gain keeps on increasing because oxidation but slower and slower because of the decreasing temperature,

- The second cooling part (low temperature) during which the sample's mass quickly and irregularly decreases because of progressive loss of the external oxide (spallation).

With this second type of mass gain plotting one finds again that there are differences of isothermal mass gains between on the one hand the two ternary alloys (rather low total isothermal mass gain) and on the other hand the three $\mathrm{Hf}$-containing alloys (final isothermal mass gain much higher). But the most interesting information concerns oxide spallation which affects all alloys but especially the Hf-containing ones because of a more important loss of oxide during cooling.

\section{High temperature oxidation kinetics: heating part and cooling part}

Before exploiting the files for obtaining the kinetic constants with accuracy, the mass gains achieved before establishment of the isothermal parabolic regime need to be known. This mass gain is the sum of the isothermal mass gain obtained during the linear transient oxidation and of the mass gain achieved during heating up to the stage temperature. The mass gain files plotted versus temperature allow determining this second contribution. By zooming on the bottom high temperature part of this graph (Fig. 6) one can see that the mass gain achieved during the heating by oxidation only is significantly lower for the Hfcontaining alloys than for the two ternary ones. Indeed, for the later ones, the total mass gains at the heating's end are effectively three times higher (the values of Mass Gain at heating "MGh" are inserted in the top-left corner of the graph). 
By zooming another time (Fig. 7) it appears that oxidation starts to be detected by the thermo-balance a little sooner (i.e. for temperatures a little lower) for the $\mathrm{Hf}$-containing alloys than for the ternary ones. The values of the oxidation start temperatures "Tstart" are inserted in the top-left corner of the graph.

By zooming on the cooling part of the curves (after having also inversed the temperature axis) one can better see the start of oxide spallation for all alloys (Fig. 8). It appears that spallation seems occurring later (i.e. for temperatures a little lower) for the Hf-containing alloys than for the ternary alloys. The values or ranges of the spallation start temperatures "Tspall" are inserted in the top-left corner of the graph. This maybe shows a little improvement of the oxide adherence as often attributed to hafnium when added (in smaller contents) to superalloys ('Ref. 10'). One can find again on this graph the more generalized oxide spallation seen above for the HfC-reinforced alloys by comparison with the ternary alloys.

\section{High temperature oxidation kinetics: isothermal oxidation}

At the beginning of the isothermal stage there is a more or less long transient oxidation during which the oxide scale becomes continuous. For the five alloys of this study this linear oxidation was very short, without any significant differences between the alloys. However the corresponding linear constant was assessed by taking the slope of the small straight line or at least of the tangent to the curve at the origin. The obtained values are presented in the first column of Table 2, in which variations can be seen but seemingly without any clear variations versus the $\mathrm{C}$ or the $\mathrm{Hf}$ contents, even if $\mathrm{KI}$ seems increasing from the Co-2 $(0.50 \% \mathrm{C})$ alloy $(0 \% \mathrm{Hf})$ to the $\mathrm{CoHfC}-2 / 1$ one $(3.7 \% \mathrm{Hf})$ and finally to the $\mathrm{CoHfC}-2 / 2$ one $(7.4 \% \mathrm{Hf})$.

After having taken into account the mass gain during heating and added them to the (small) linear mass gain of transient oxidation, the mass gain were plotted versus the square root of time to assess the parabolic constants. The obtained $\mathrm{Kp}$ values are given in the second column of Table 2. It appears that the Kp obtained for the ternary alloys are rather low, in accordance with values generally found (without consideration of chromia volatilization) for chromia-forming alloys in air at $1200^{\circ} \mathrm{C}$ '(Ref. 10)'. In contrast the Kp values determined for the HfC-reinforced alloys, which are about ten times higher than for the ternary alloys, are not typical of a protection by chromia. The $\{m \times d m / d t=K p-m \times K v\}$-based method (Fig. 9) leads, for the ternary alloys, to values of $\mathrm{Kp}$ and $\mathrm{Kv}$ in the neighborhood of what is generally obtained for chromia-forming cast alloys '(Ref. 19)' while the values of both constants determined for the HfC-reinforced alloys are especially high, except for the CoHfC-2/1 alloy for which a negative $\mathrm{Kv}$ was found ('this is often due to a linear oxidation on a part of the alloy (Ref. 22)').

The mathematical curves plotted using the two sets of kinetic constants, Kp only ("math 1") or Kp and Kv ("math 2"), are superposed with the experimental curves ("exp") in Fig. 10 (example of the Co-1 alloy) and in Fig. 11 (examples of the CoHfC-2/1 and CoHfC-2/2 alloys). One can see that the (Kp, Kv)-curve better fits the experimental curve for the Co-2 alloy than the (Kp only)-curve, but only for the parabolic part preceding the linear oxidation. The fit is worse for the CoHfC-2/1 and CoHfC-2/2 alloys although the end-part parallelism 
between the mathematical curve and the experimental curve is better for the (Kp, Kv)-curve than for the (Kp only)-curve.

\section{Characterization of the oxidized surfaces and sub-surfaces}

Before any metallographic preparation the oxidized surfaces were analyzed by X-ray diffraction (example of CoHfC-2/2 in Fig. 12). The HfC-reinforced alloys are covered by many types of oxides: $\mathrm{CoO}, \mathrm{Co}_{3} \mathrm{O}_{4}$, spinel $\mathrm{CoCr}_{2} \mathrm{O}_{4}$ and $\mathrm{Cr}_{2} \mathrm{O}_{3}$ for the ternary alloys and the 3.7wt.\%Hf-containing alloys for which peaks of austenitic and hexagonal Co matrixes appear too. The $\mathrm{Hf}$-richest alloy is covered by a mixed oxides scale composed of $\mathrm{Cr}_{2} \mathrm{O}_{3}$, spinel $\mathrm{CoCr}_{2} \mathrm{O}_{4}$ and additionally a small quantity of $\mathrm{HfO}_{2}$ oxide.

This was confirmed by cross-section SEM observations and EDS pinpoint measurements, as illustrated in Fig. 13 for the ternary alloys and in Fig. 14 for the HfC-reinforced alloys. However the external surface was not entirely affected by catastrophic oxidation since there remain some zones in which oxidation was obviously not yet generalized and even still covered by chromia. One can notice on the preceding micrographs that no carbide-free zone finally developed from the oxide/alloy interface. Thus no $\mathrm{Hf}$ atoms were released in matrix and can be available to diffuse toward the oxidation front and take part to a scale adherence improvement.

EDS concentration profiles were acquired through the sub-surface perpendicularly to the oxide/alloy interface (examples of Co-2 and CoHfC-1/1 in Fig. 15 and of CoHfC-2/1 and CoHfC-2/2 in Fig. 16). The Cr-depletion was about 150um-deep for all alloys and the chromium content in the extreme surface of the alloys was about $15 \mathrm{wt} \%$ where oxidation obviously started to accelerate, higher where the alloy was still chromia-forming and lower where catastrophic oxidation penetrated inward the bulk.

\section{Discussion:}

The alloys elaborated with the tested hafnium contents in their chemical compositions were successfully obtained with a lot of hafnium carbides, mainly as eutectic $\mathrm{HfC}$ mixed with matrix in the interdendritic spaces. These three alloys can be effectively called ' $\mathrm{HfC}$ reinforced cobalt-based alloys'. The especially strong carbide-forming character of hafnium involves the carbon atoms in the formation of $\mathrm{HfC}$ carbides exclusively and the second type of possible carbides (chromium carbides), involving the second carbide-forming element stronger than cobalt, only if there are some carbon atoms in excess. To summarize, it is the $\mathrm{Hf}$ content, and not the carbon content, which directly governs the $\mathrm{HfC}$ quantity in these alloys.

It was also seen that the presence of hafnium seems having a beneficial effect on the oxidation during heating by lowering the final mass gain achieved when reaching $1200^{\circ} \mathrm{C}$, by comparison with the ternary alloys. The presence of a so reactive element, which is maybe responsible of the lower temperature of oxidation start than for the ternary alloys, had an effect which remains to explain. Concerning the spallation at cooling, it is possible to think that, although $\mathrm{Hf}$ seemed to be entirely trapped into very stable carbides, some hafnium atoms were however still available in the matrix and diffused towards the surface during the 
isothermal stage and then acted as commonly encountered in Hf-doped superalloys '(Ref. 10)'. One saw here that this is obviously not the case since no carbide-free zone developed from the oxidation front. Consequently no hafnium atoms were released by these too stable carbides and then no $\mathrm{Hf}$ atoms diffused to the oxide/alloy interface. The improvement of the scale adherence which was observed, in terms of lower temperature of spallation beginning, must be attributed to another factor, maybe the presence of $\mathrm{HfO}_{2}$ resulting of the oxidation of $\mathrm{HfC}$ carbides trapped in the growing oxide scales.

The determined kinetic constants were compatible with a chromia-forming behavior for the ternary alloys only, and this not over the total 50 hours since the oxidation of Co- 1 became linear after about 25h. The HfC-reinforced alloys, which oxidized with a parabolic law too but much faster have obviously never behaved as chromia-forming. This was obvious by considering first the very high $\mathrm{Kp}$ values obtained. In their cases the $(\mathrm{Kp}, \mathrm{Kv})$ determination is evidently out of subject since no chromia exists and cannot undergo volatilization.

The metallographic characterizations confirmed that, in all cases, the alloys were effectively affected by catastrophic oxidation, sooner (the HfC-reinforced alloys) or later (the ternary alloys). This explains the fast parabolic kinetics of the HfC-reinforced alloys and, by comparison with the ternary alloys, their higher final mass gain and thicker oxide scales existing on their surfaces at the end of the isothermal stages. This is also the reason of the greater mass loss by oxide spallation when this occurred during the cooling.

The behaviour in high temperature oxidation of the studied HfC-reinforced alloys is thus inacceptable in its actual state for applications at a so high temperature of $1200^{\circ} \mathrm{C}$. Indeed they take no benefit of the presence of $25 \mathrm{wt} . \%$ of chromium and they oxidize too fast since the first moments. The oxide spallation observed at a so low cooling rate as $5^{\circ} \mathrm{C}$ per minute let think that such alloys may behave dramatically in cyclic oxidation. These alloys are then not better than the ternary Co-25Cr- 0.25 or $0.50 \mathrm{C}$ simple alloys which are known to be not very resistant in oxidation at high temperature. Fortunately several ways of improvements exist:

- Increasing the chromium content up to $30 \mathrm{wt}$ \% or slightly more, for delay the decrease down to the apparently fatidic $15 \mathrm{wt} . \% \mathrm{Cr}$ on extreme surface, but with as possible consequence a loss of refractoriness for the alloy and then of creep resistance,

- Adding slightly more $\mathrm{Hf}$ to excess the quantity necessary to form only HfC carbides, for an availability of this element in matrix to diffuse toward the oxidation front to bring more adherence to the oxide scales,

- Eventually taking benefit of the high stability of the $\mathrm{HfC}$ carbides to enrich sub-surface in chromium using $\mathrm{Cr}$-pack cementation without problem of formation of a chromium carbide continuous zone obstructing the inwards $\mathrm{Cr}$ diffusion process as previously encountered in cobalt alloys containing initially chromium carbides.

\section{Conclusions:}

The hafnium addition in sufficient quantities in cobalt-based alloys already containing carbon may lead to the development of a potentially efficient interdendritic carbides network, with a script-like shape allowing potentially good mechanical properties at high temperature, as 
proven with 'interdendritic eutectic TaC carbides in other equi-axed cast cobalt-based superalloys (Ref. 23)'. Unfortunately their oxidation behaviours at high temperature in air remain to be significantly improved, objectives for which several possibilities potentially efficient exist and will be tested in further work. However, despite that all alloys suffered fast and even catastrophic oxidation, interesting behaviour differences by comparison with similar but $\mathrm{Hf}$-free ternary alloys were seen and explained.

\section{Acknowledgements:}

The authors would like thank Pascal Villeger for the XRD experiments.

\section{References:}

1. C. T. Sims and W. C. Hagel (eds.): 'The Superalloys'; 1972, New York, John Wiley \& Sons.

2. C.T. Sims, N.S. Stoloff and W.C. Hagel (eds): 'Superalloy II - High temperature materials for aerospace and industrial power'; 1987, New York, John Wiley.

3. P. Berthod, S. Michon, L. Aranda, S. Mathieu and J.C. Gachon: 'Experimental and thermodynamic study of the microstructure evolution in cobalt-base superalloys at high temperature', Calphad, 2003, 27, 353-359.

4. M. J. Donachie and S. J. Donachie (eds): 'Superalloys - A technical guide ( $2^{\text {nd }}$ ed.)'; 2002, Materials Park, ASM International.

5. P. Berthod, C. Heil and L. Aranda: 'Influence of the morphologic evolution of the eutectic carbides at high temperature on the thermal expansion behaviour of refractory cast alloys', J. Alloys Compds., 2010, 504, 243-250.

6. P. Berthod, S. Michon, L. Aranda and P. Steinmetz: 'Consequences of the high temperature microstructure evolution on the tensile properties at high temperature of a cobalt-based superalloys reinforced by tantalum carbides', Proc. 'Matériaux 2006', Dijon, France, November 2006.

7. P. Berthod, L. Aranda and C. Heil: 'Effect of a preliminary aging treatment on the oxidation kinetic at high temperature for a cobalt-based alloy strengthened by tantalum carbides', Open Corr. J., 2009, 2, 150-156.

8. P. Berthod: 'High temperature properties of several chromium-containing Coèbased alloys reinforced by different types of $\mathrm{MC}$ carbides ( $\mathrm{M}=\mathrm{Ta}, \mathrm{Nb}, \mathrm{Hf}$ and/or $\mathrm{Zr}$ )', J. Alloys Compds., 2009, 481, 746-754.

9. P. Kofstad: 'High temperature corrosion'; 1988, London, Elsevier applied science.

10. D. J. Young: 'High temperature oxidation and corrosion of metals'; 2008, Amsterdam, Elsevier.

11. W. S. Lee and G. M. Kim: 'The effect of $\mathrm{Hf}, \mathrm{Y}$ and $\mathrm{Zr}$ additions on the oxidation behaviour of Ni-based Inconel 601 at high temperature', Han'guk Pusik Hakhoechi, 1995, 24, 124-133.

12. N. Maragoudakis, D. Tsipas and V. Eggonopoulos-Papadopoulos: 'The role of reactive elements on scale adherence in high-temperature oxidation behaviour of metals and alloys', Romanian Journal of Physics, 2004, 49, 245-250. 
13. K. Ishii, M. Kohno, S. Ishikawa and S. Satoh: 'Effect of $\mathrm{Ti}, \mathrm{Zr}$ and $\mathrm{Hf}$ on hightemperature oxidation resistance of Fe-20Cr-5Al-0.1La alloy foils', Materials Transactions JIM, 1998, 39, 1040-1045.

14. T. Amano, T. Ozawa, K. Kudo, N. Matsumoto, N. Sakai and H. Isobe: 'Hightemperature oxidation of heat-resistant iron alloy containing small amounts of $S$ and $Y$ or Hf for 1800ks at 1373 K', Journal of Advanced Science, 2001, 13, 64-65.

15. X. Chunmei, J. Guo and F. Yang: 'High-temperature oxidation behaviour of NiAl28Cr-5Mo-1Hf alloy', Jinshu Xuebao, 2001, 37, 857-860.

16. Z. Wang, L. Zhou, J. Guo, Y. Liang and Z. Hu: 'High temperature oxidation behaviour of directional solidification NiAl-28Cr-5.94Mo-0.05Hf-0.01Ho eutectic alloy', Cailiao Yanjiu Xuebao, 2010, 24, 585-591.

17. H. Guo, L. Sun, H. Li, S. Gong: 'High temperature oxidation behaviour of hafnium modified NiAl bond coat in EB-PVD thermal barrier coating system', 2008, Thin Solid Films, 516, 5732-5735.

18. P. Song, J. Lu, D. Zhang, J. Lu and D. Li: 'Effect of La and Hf dopant on the high temperature oxidation of CoNiCrAl alloys', Jinshu Xuebao, 2011, 47, 655-662.

19. P. Berthod: 'Kinetics of high temperature oxidation and chromia volatilization for a binary Ni-Cr alloy', Oxid. Met., 2005, 64, 235-252.

20. P. Berthod: 'Thermogravimetric study of oxide spallation for chromium-rich cast cobalt-based and iron based alloys oxidized at high temperature', Open Corr. J., 2009, 2, 61-70.

21. P. Berthod: 'Oxidation start detection on heating parts of thermogravimetry curves for high temperature alloys based on nickel, cobalt or iron', Open Corr. J., 2011, 4, 1-8.

22. P. Berthod: 'Influence of the base element and of the carbides' density on the high temperature oxidation of $\mathrm{M}-30 \mathrm{Cr}-\mathrm{xC}$ alloys $(\mathrm{M}=\mathrm{Co}, \mathrm{Ni}, \mathrm{Fe})$. Part I: Parabolic and $\mathrm{Cr}_{2} \mathrm{O}_{3}$-volatilization kinetic constants', Ann. Chim. Sci. Mat., 2008, 33, 225-245.

23. P. Berthod, J.L. Bernard and C. Liébaut: 'Cobalt-chromium alloy for spinner cups in manufacture of mineral wool from silicate glass', International Patent (2001) WO2001090429 


\section{TABLES}

Table 1. Chemical compositions of the five studied alloys (all contents in weight percents); C targeted, $\mathrm{Cr}$ and $\mathrm{Hf}$ : EDS measurements

\begin{tabular}{|c|c|c|c|}
\hline Weight contents & Carbon & Chromium & Hafnium \\
\cline { 2 - 4 } & targeted & $\begin{array}{c}\text { Average } \\
\pm \text { tsandard } \\
\text { deviation }\end{array}$ & $\begin{array}{c}\text { Average } \\
\text { dstandard } \\
\text { deviation }\end{array}$ \\
\hline Co-1 & 0.25 & $\mathbf{2 5 . 4} \pm 0.2$ & $/$ \\
\hline Co-2 & 0.50 & $\mathbf{2 4 . 3} \pm 1.5$ & $/$ \\
\hline CoHfC-1 & 0.25 & $\mathbf{2 5 . 4} \pm 0.2$ & $\mathbf{4 . 0} \pm 0.3$ \\
\hline CoHfC-2/1 & 0.50 & $\mathbf{2 5 . 8} \pm 0.3$ & $\mathbf{3 . 5} \pm 0.2$ \\
\hline CoHfC-2/2 & 0.50 & $\mathbf{2 5 . 4} \pm 0.7$ & $\mathbf{1 0 . 2} \pm 2.0$ \\
\hline
\end{tabular}

Table 2. Values of the kinetic constants determined on the mass gain files

\begin{tabular}{|c|c|c|c|c|}
\hline \multirow{3}{*}{ Kinetic constants } & \multicolumn{4}{|c|}{$\begin{array}{c}\mathrm{KI}\left(\times 10^{8} \mathrm{~g} \mathrm{~cm}^{-2} \mathrm{~s}^{-1}\right), \mathrm{Kp}\left(\times 10^{12} \mathrm{~g}^{2} \mathrm{~cm}^{-4} \mathrm{~s}^{-1}\right) \\
\text { and } \mathrm{Kv}\left(\times 10^{10} \mathrm{~g} \mathrm{~cm}^{-2} \mathrm{~s}^{-1}\right)\end{array}$} \\
\hline & \multirow{2}{*}{$\mathrm{KI}$} & \multirow{2}{*}{$\mathrm{Kp}$} & \multicolumn{2}{|c|}{ 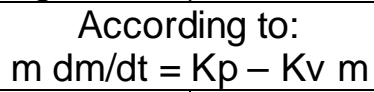 } \\
\hline & & & $K p$ & Kv \\
\hline Co-1 & 61.6 & 80.5 & 137 & 232 \\
\hline Co-2 & 32.3 & 58.5 & 127 & 224 \\
\hline CoHfC-1 & 42.0 & 830 & 2510 & 473 \\
\hline CoHfC-2/1 & 40.4 & 815 & 740 & $-133\left(^{*}\right)$ \\
\hline CoHfC-2/2 & 79.9 & 585 & 1330 & 530 \\
\hline
\end{tabular}




\section{FIGURES}
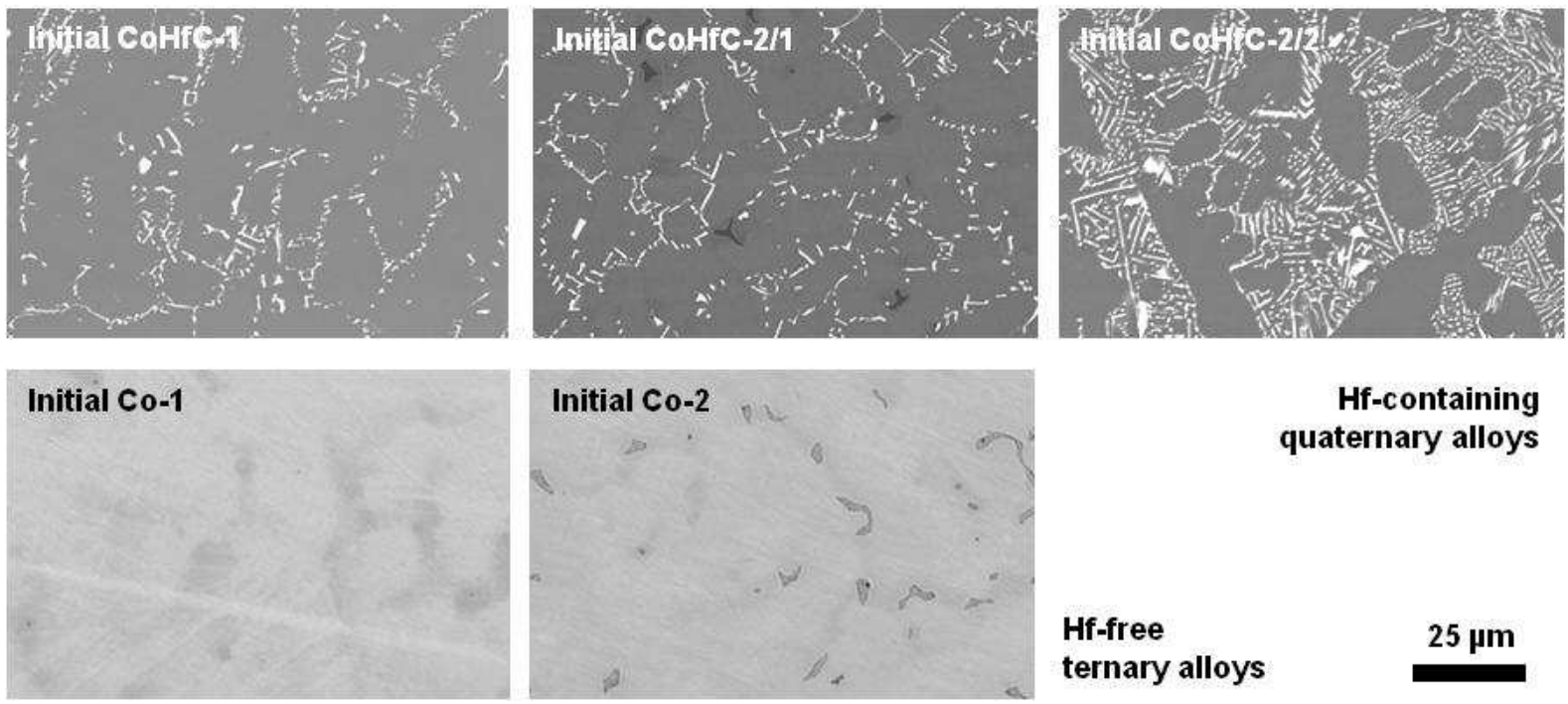

Hf-containing quaternary alloys

Hf-free

ternary alloys

$25 \mu \mathrm{m}$

Fig. 1. Microstructures of the five alloys after casting (SEM/BSE examinations)
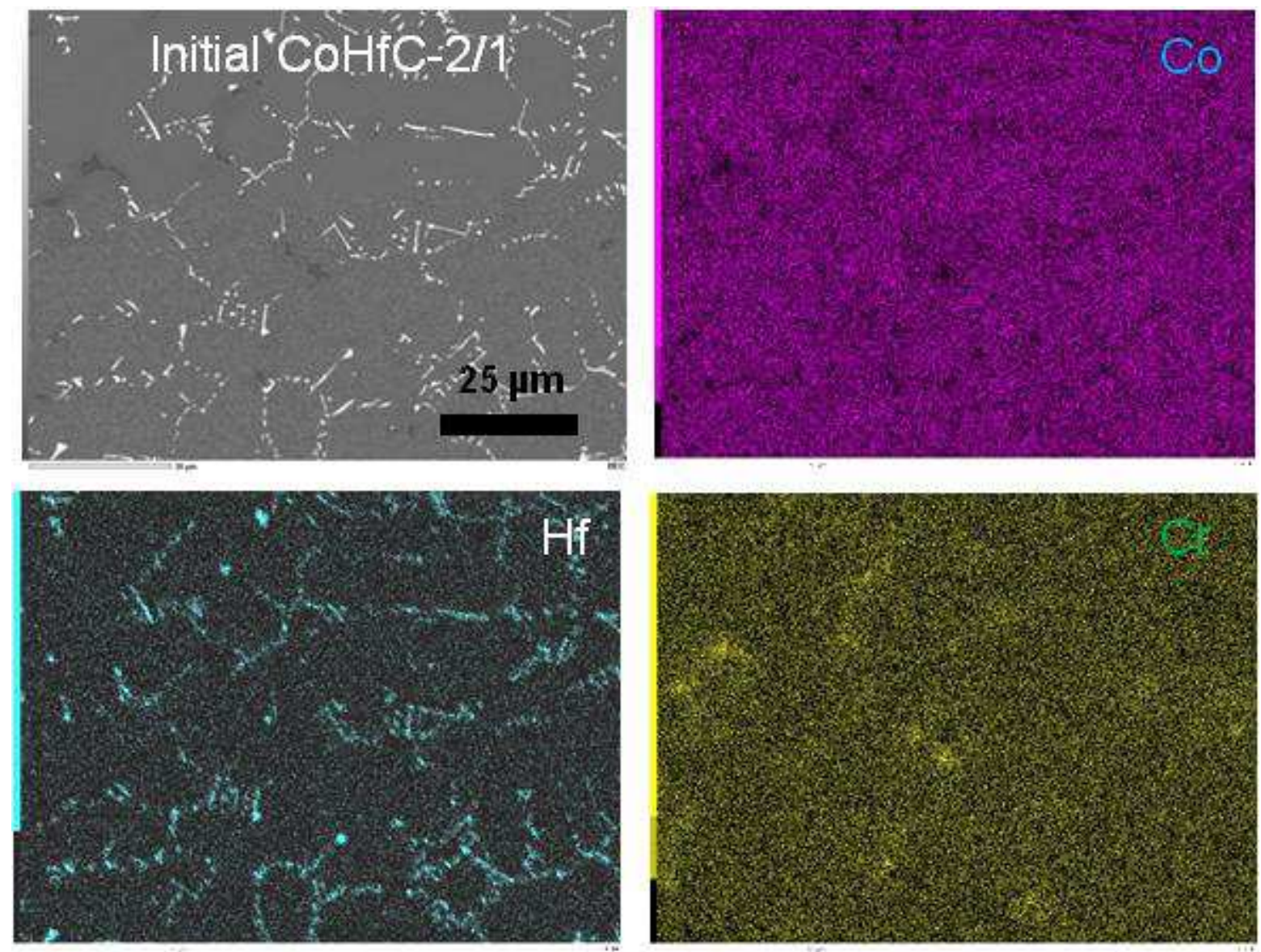

Fig. 2. X-ray maps for revealing the HfC carbides and Cr-carbides in the CoHfC-2/1 alloy (SEM/BSE examinations) 


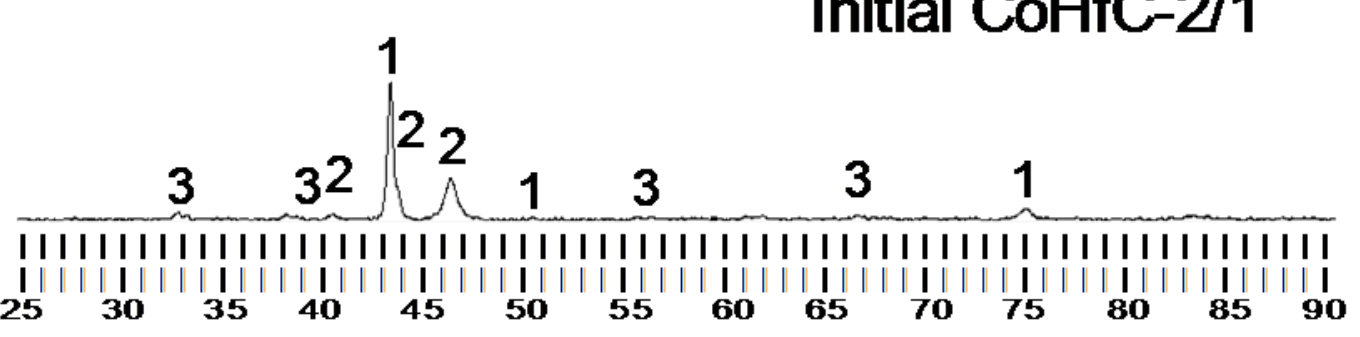

\section{1: Co fcc, 2: Co hcp, 3: HfC carbides}

Fig. 3. Diffractogram revealing the $\mathrm{HfC}$ carbides and the double-type matrix in the CoHfC-2/1 alloy

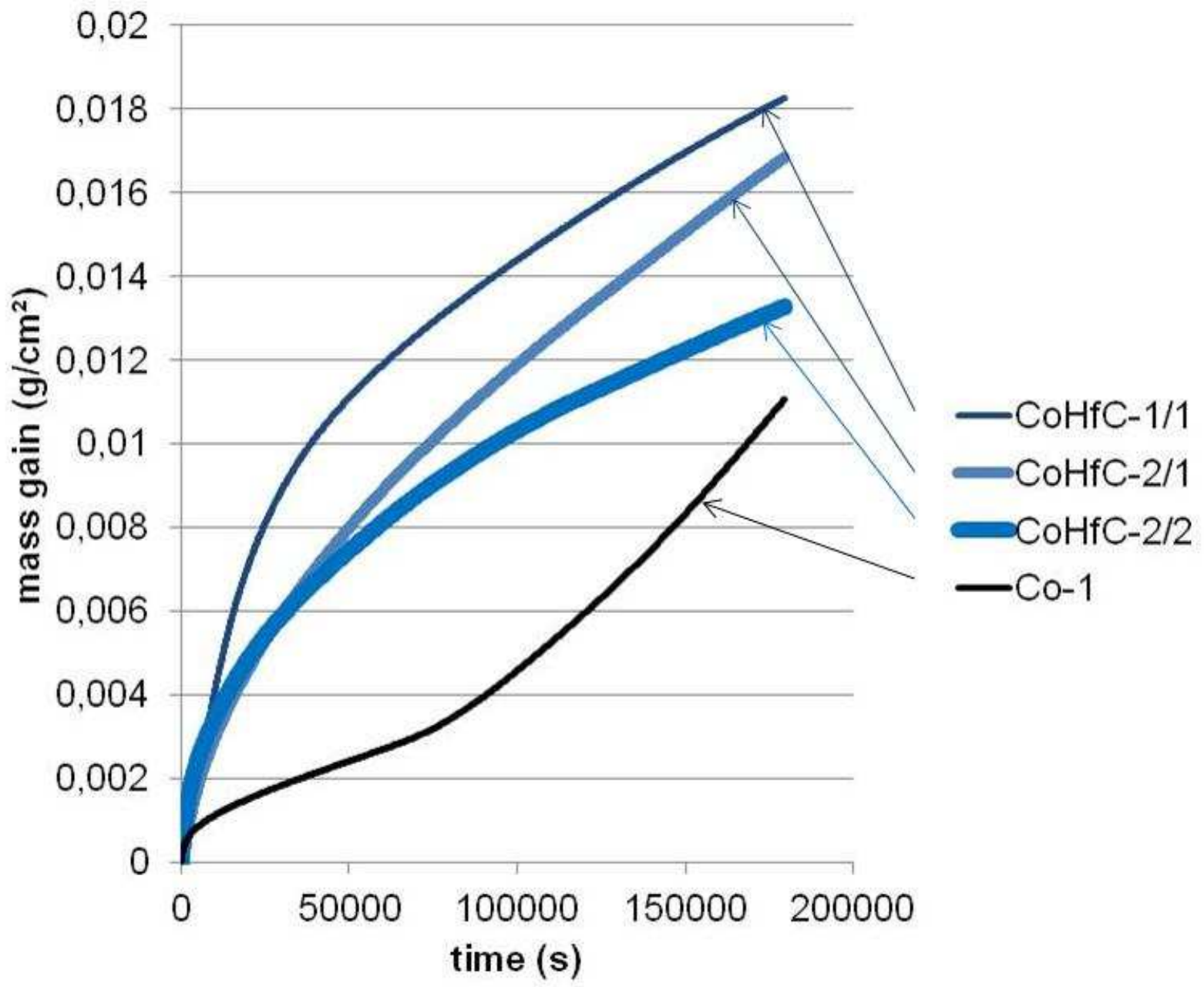

Fig. 4. Mass gain curves recorded for the three HfC-reinforced alloys and for one of the ternary alloys for comparison 


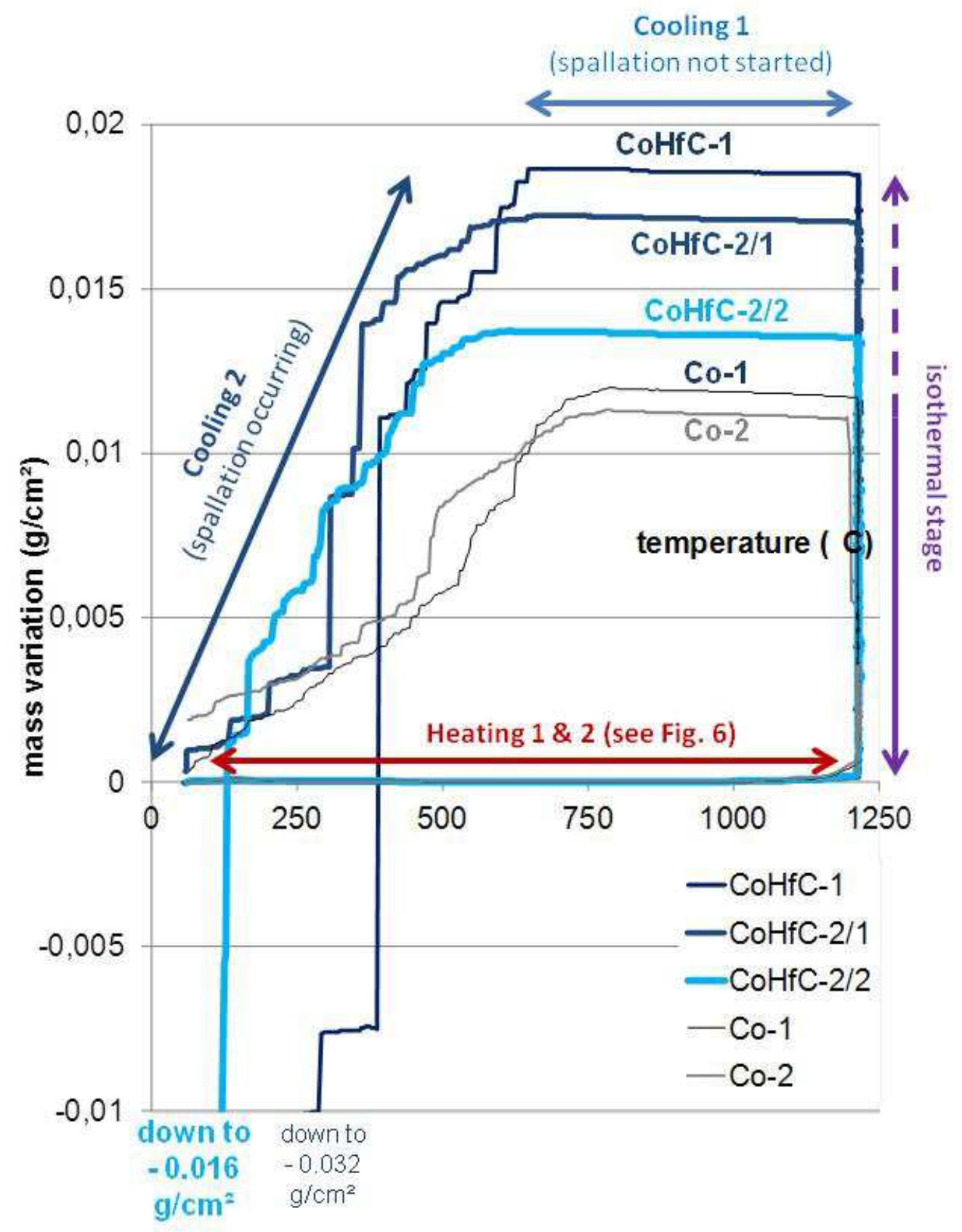

Fig. 5. Heating, isothermal stage and cooling parts of the thermogravimetry curves obtained by plotting mass gain versus temperature instead time; highlighting the oxidation start at heating and the oxide spallation at cooling (corrected from air buoyancy) 


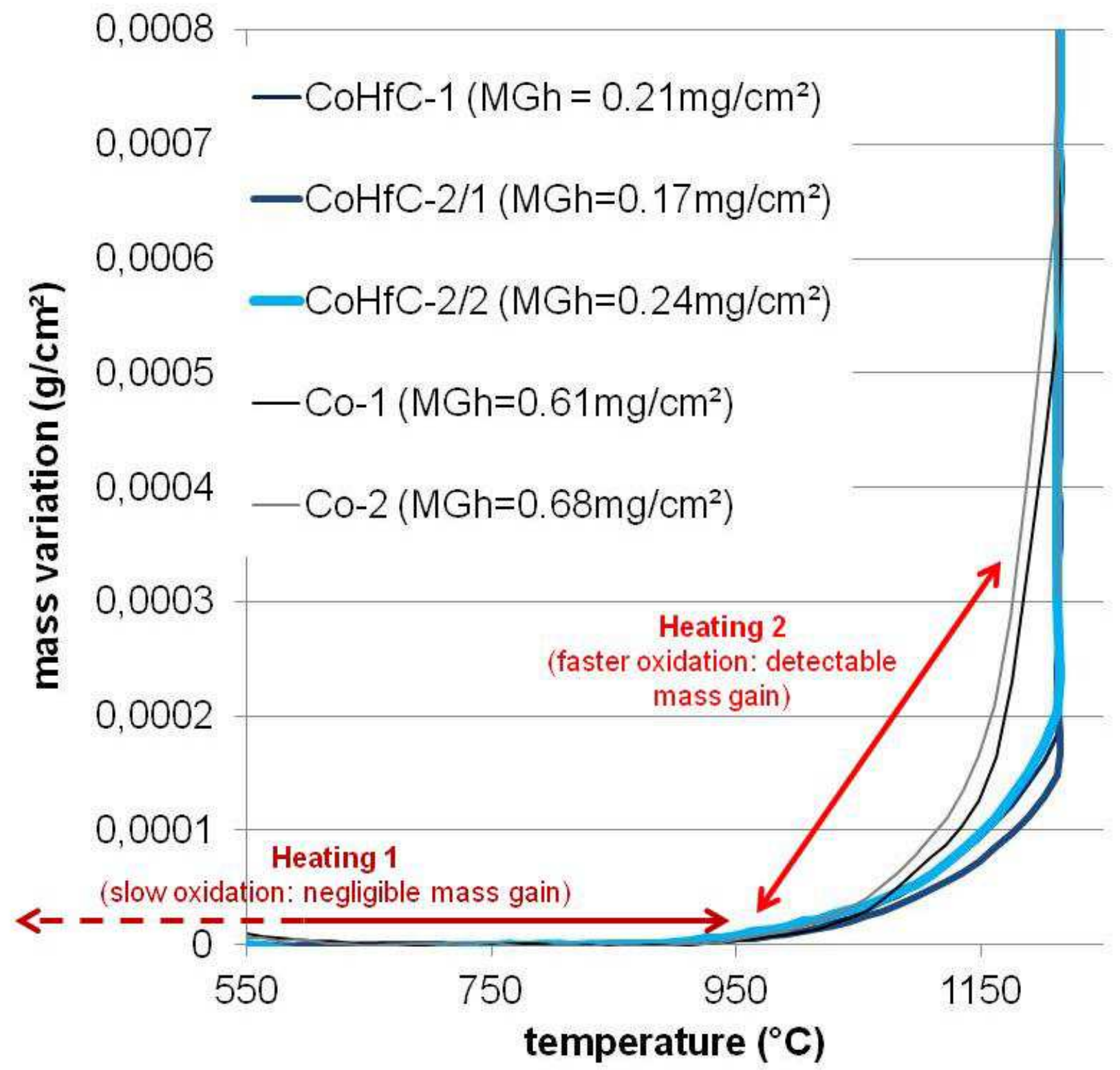

Fig. 6. Medium magnitude enlargement of figure 5 evidencing the total mass gain achieved during the whole heating (inserted: values of the heating mass gains red on these curves) 


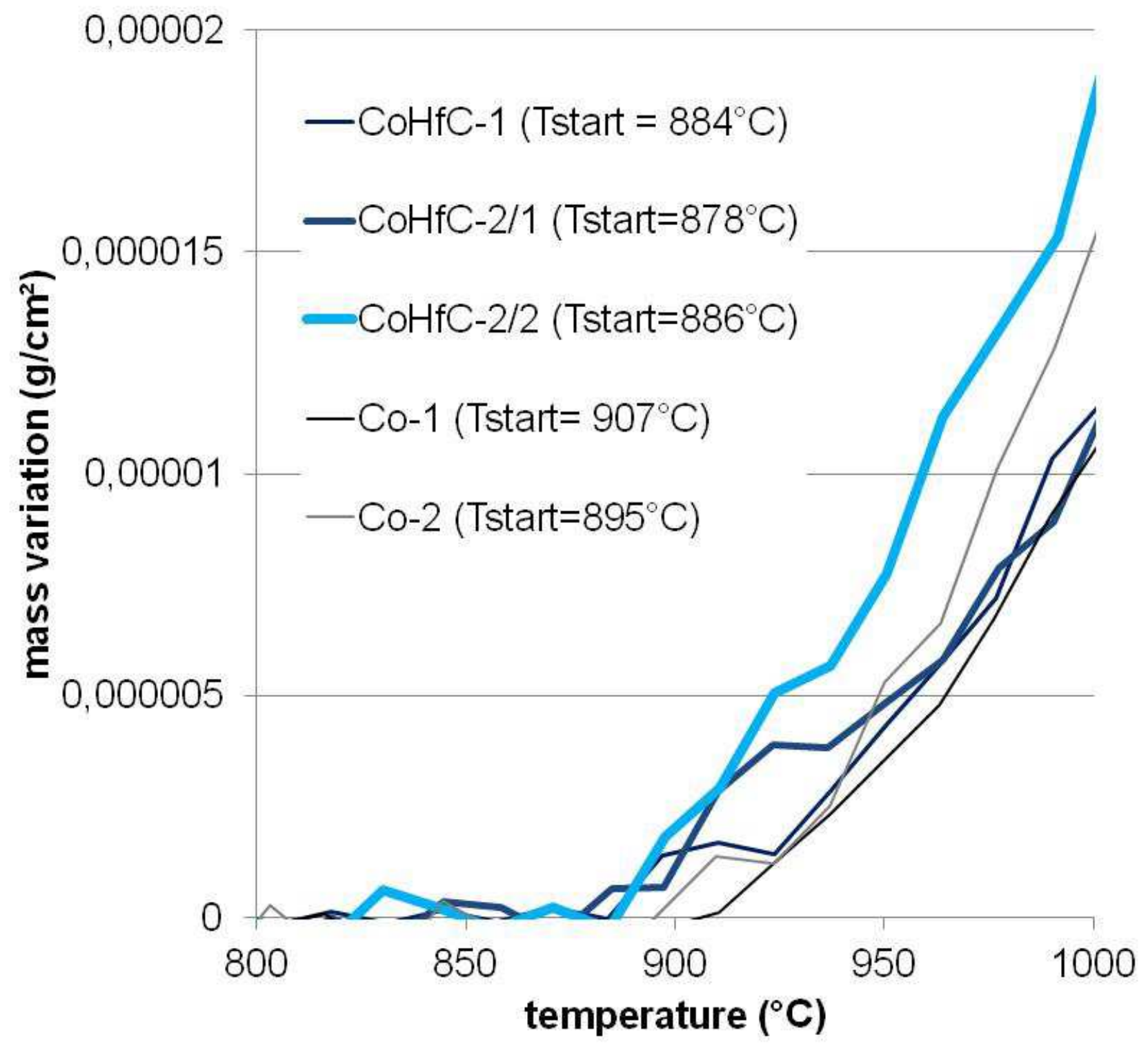

Fig. 7. High magnitude enlargement of figure 5 evidencing the start of oxidation at heating defined as first mass gain detectable by the used thermobalance (inserted: values of the oxidation start temperatures red on these curves) 


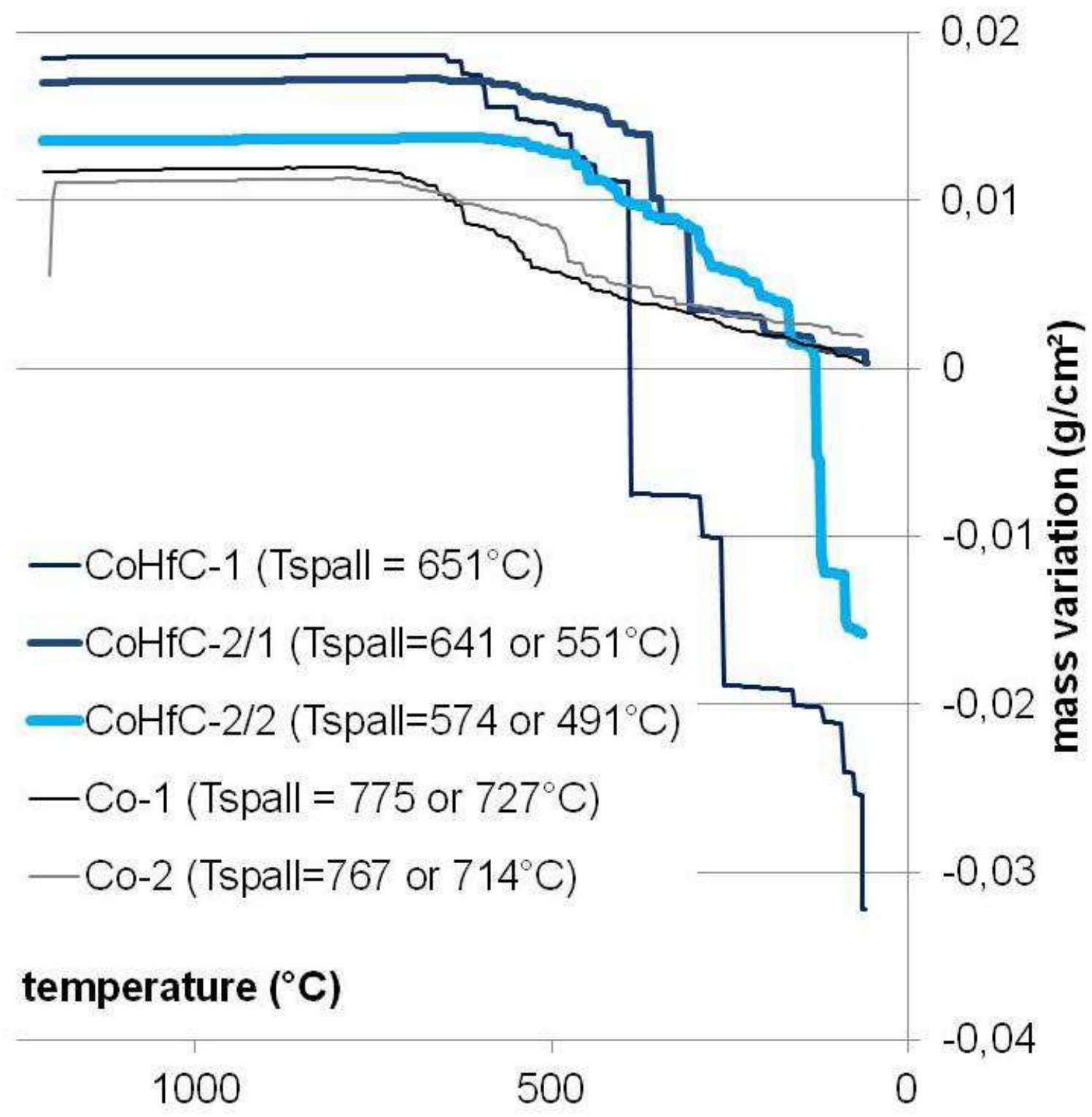

Fig. 8. Low magnitude enlargement of figure 5 evidencing the oxide spallation during the cooling ( $x$-axis: inverse order for temperature values)

(inserted: the values of the temperatures at which - or temperature range in which oxide spallation started) 


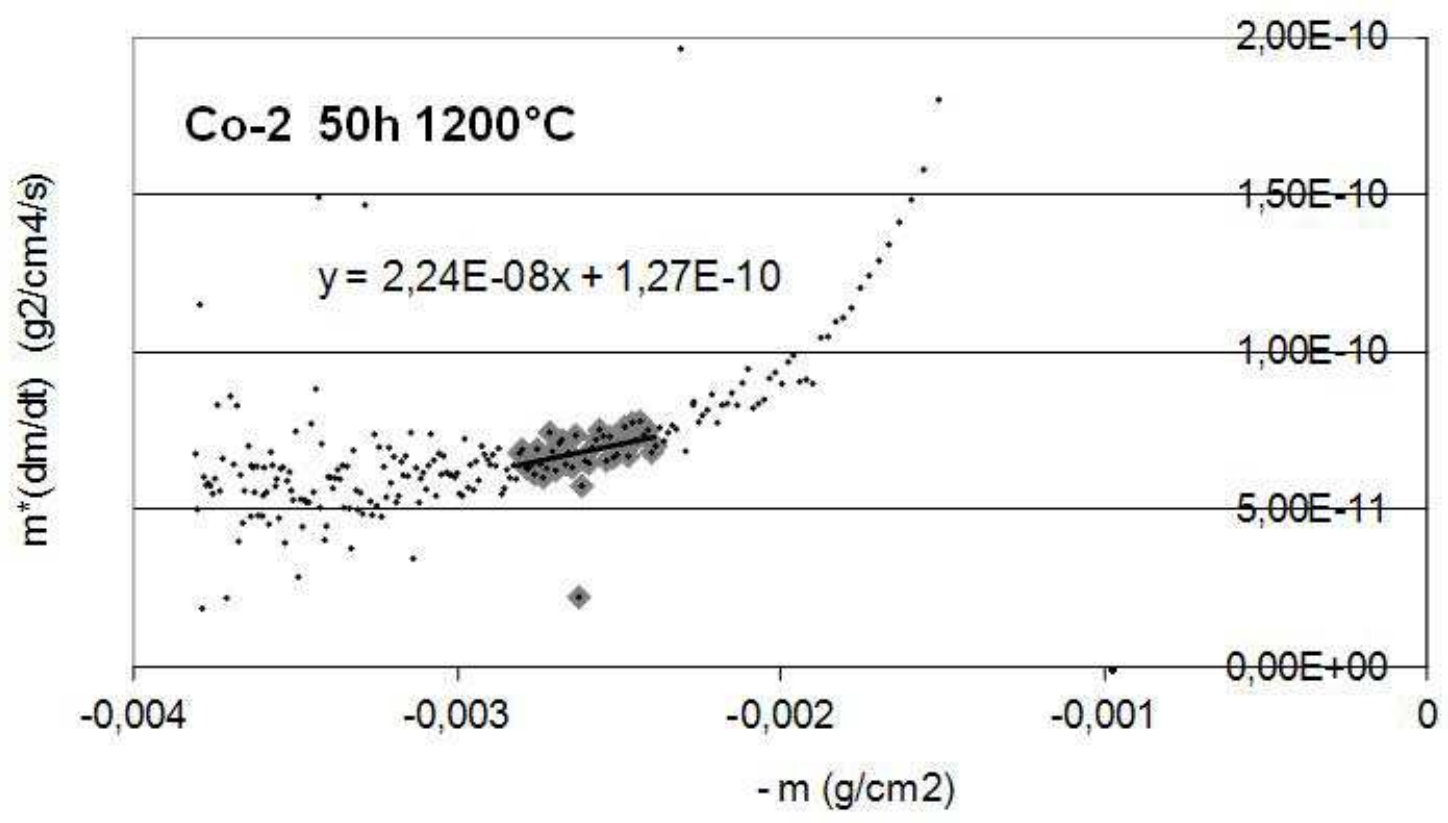

Fig. 9. Example of plotting the mass gain values according to the $\{m \times d m / d t=f(-m)$ $=\mathrm{Kp}-\mathrm{m} \times \mathrm{Kv}\}$ to specify the isothermal kinetic constants $\mathrm{Kp}$ and $\mathrm{Kv}$ 


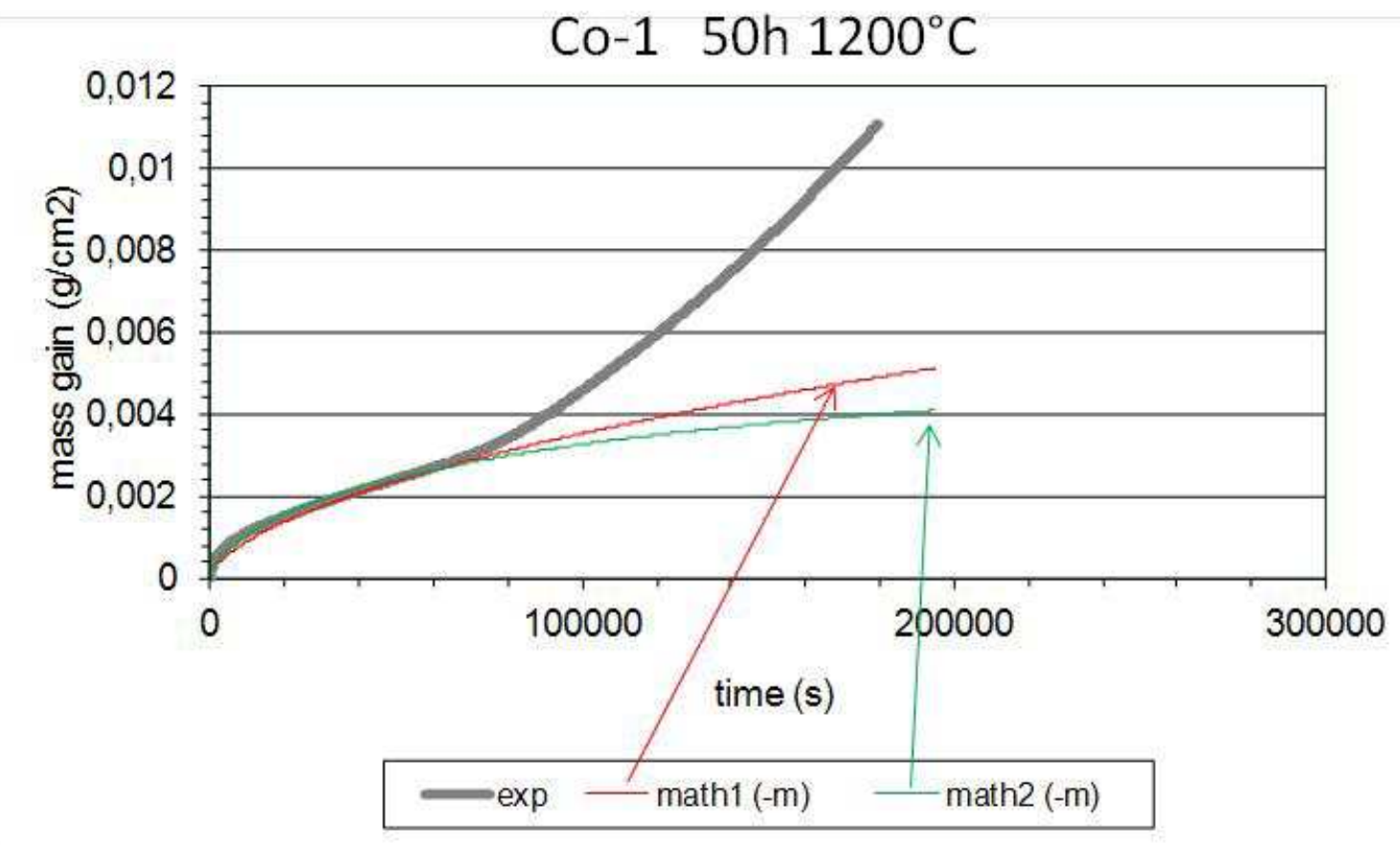

Co-1 $50 \mathrm{~h} 1200^{\circ} \mathrm{C}$ (enlarged)

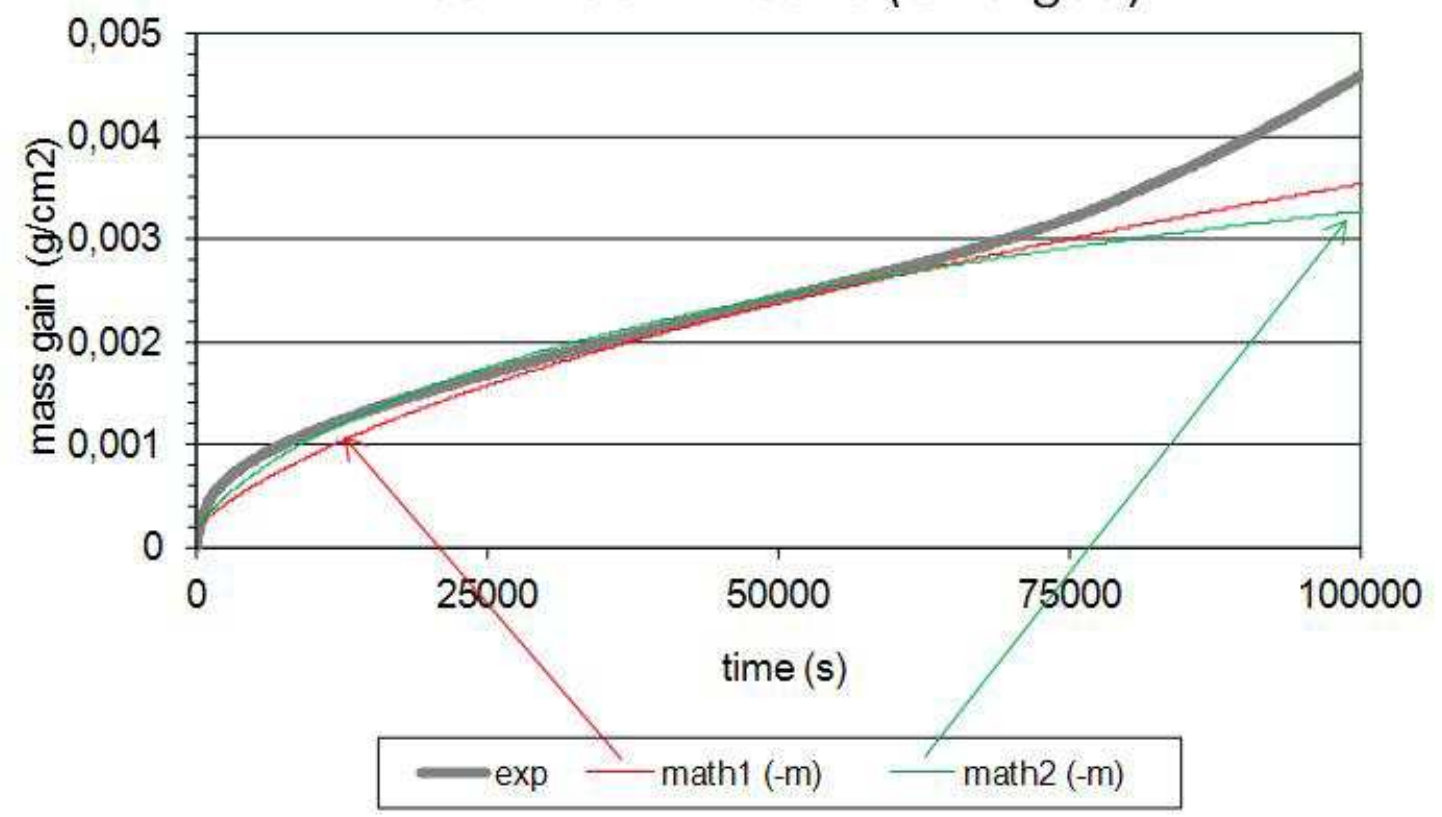

Fig. 10. Comparison, with the experimental mass gain curve ("exp"), of the mathematical curve drawn using the value of Kp only (issued from conventional determination of parabolic constant, "math1") and of the mathematical curve drawn using the values of $\mathrm{Kp}$ and $\mathrm{Kv}$ (issued from the treatment according to $\{\mathrm{m} \times \mathrm{dm} / \mathrm{dt}=$ $f(-m)=K p-m \times K v\}$, "math2"); here case of one of the ternary alloys the behaviour of which were chromia-forming at the beginning of the isothermal stage 


\section{CoHfC-2/1 50h $1200^{\circ} \mathrm{C}$}
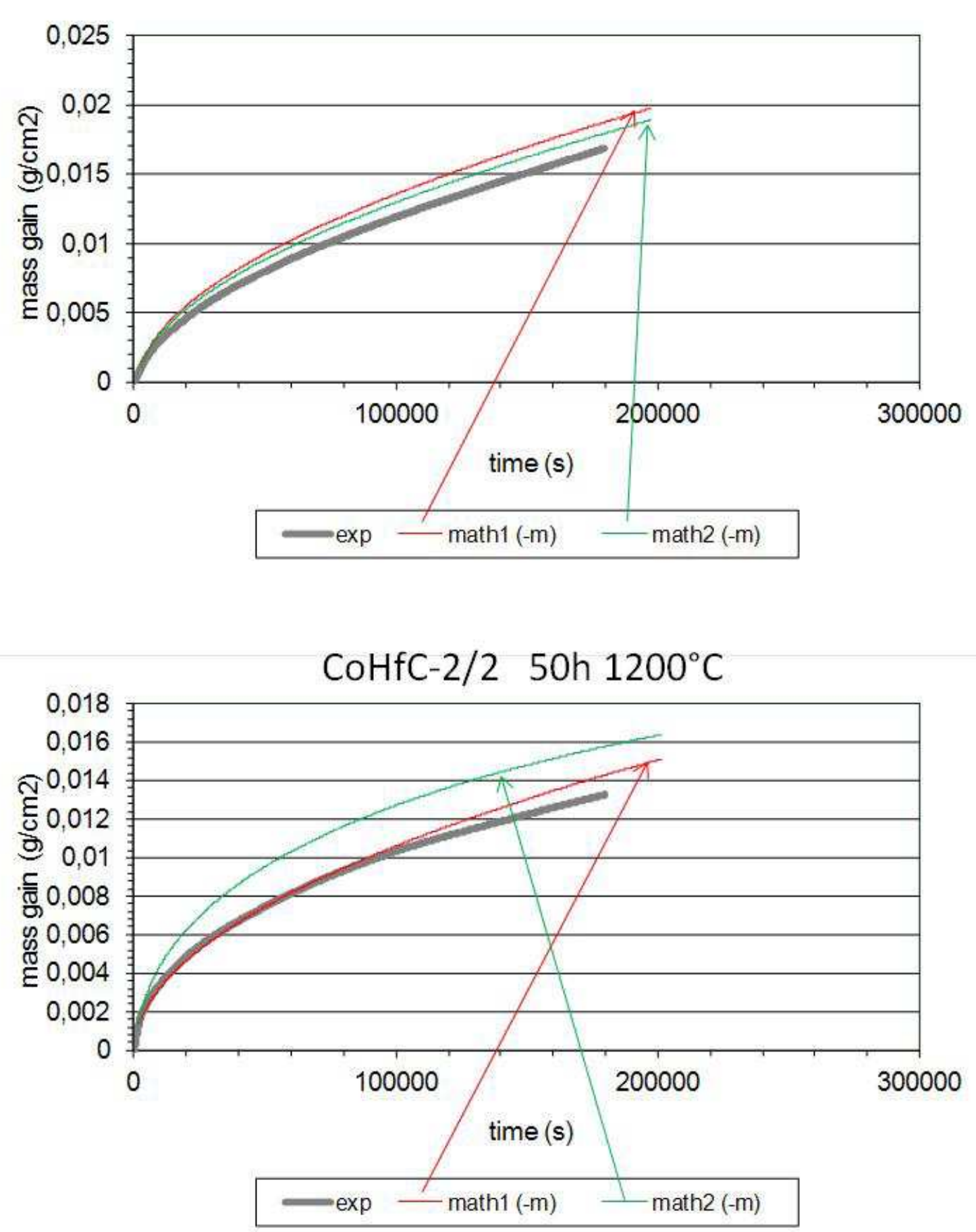

Fig. 11. Comparison, with the experimental mass gain curve ("exp"), of the mathematical curve drawn using the value of Kp only (issued from conventional determination of parabolic constant, "math1") and of the mathematical curve drawn using the values of $\mathrm{Kp}$ and $\mathrm{Kv}$ (issued from the treatment according to $\{\mathrm{m} \times \mathrm{dm} / \mathrm{dt}=$ $\mathrm{f}(-\mathrm{m})=\mathrm{Kp}-\mathrm{m} \times \mathrm{Kv}\}$, "math2"); here case of two of the HfC-reinforced alloys the ternary alloy Co-1 the behaviours of which were not chromia-forming during the whole isothermal stage 


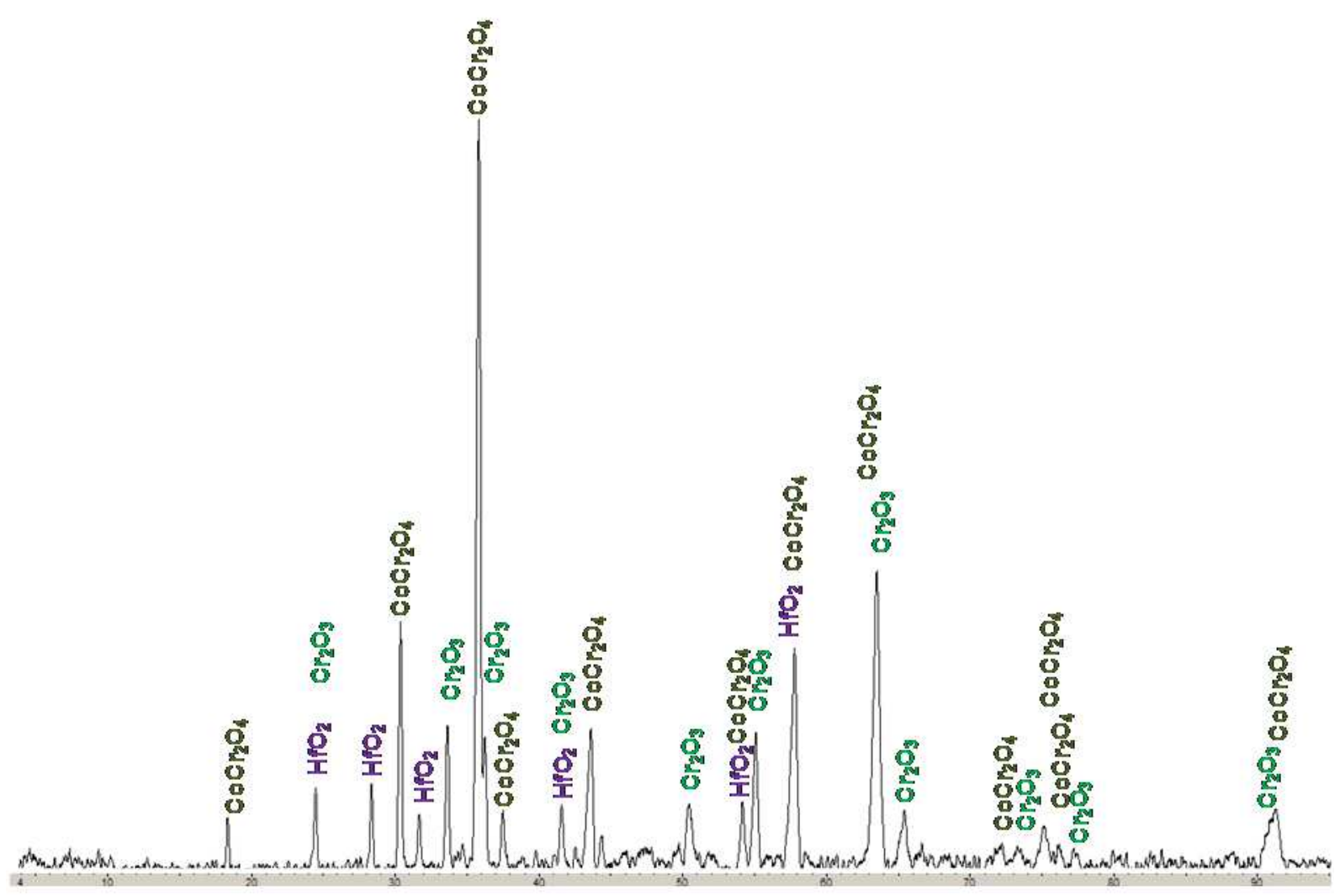

CoHfC-2/2 after 50 h of oxidation at $1200^{\circ} \mathrm{C}$

Fig. 12. Diffractogram acquired on the oxidized surface of one of the HfC-reinforced alloys, evidencing the multiple nature of the scale (chromia, spinel oxide and hafnium oxide) 


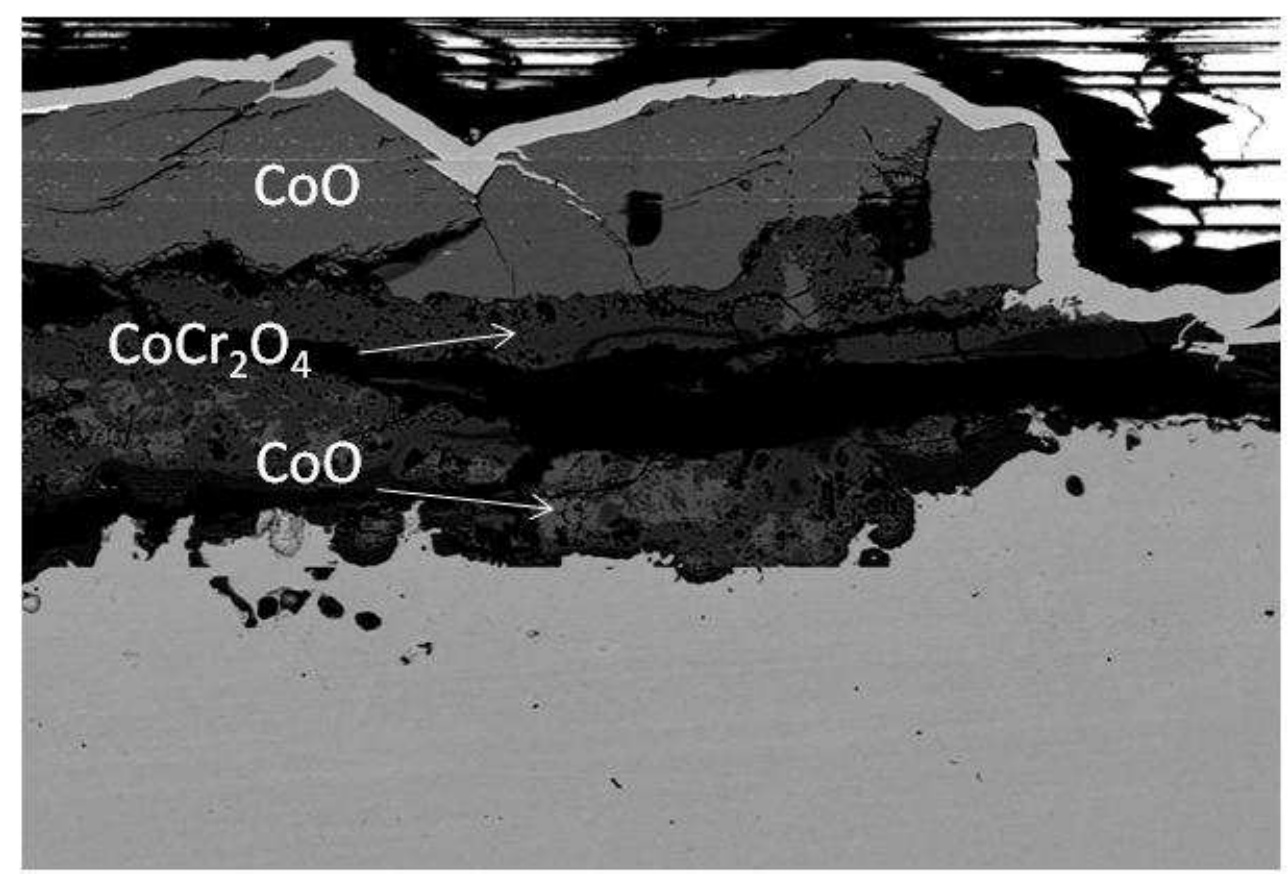

Co-1 oxidized $50 \mathrm{~h}$ at $1200^{\circ} \mathrm{C}$

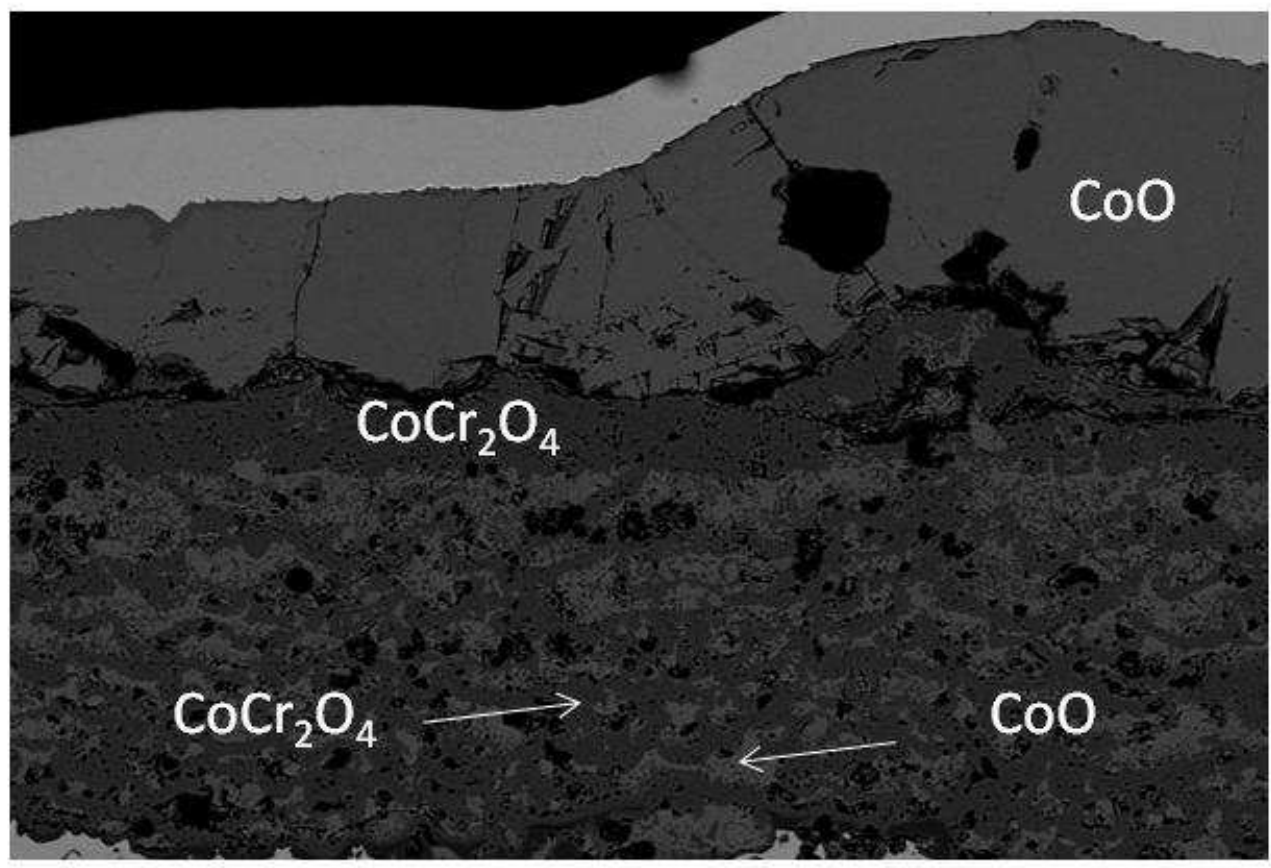

Co-2 oxidized $50 \mathrm{~h}$ at $1200^{\circ} \mathrm{C}$

$100 \mu \mathrm{m}$

Fig. 13. Illustration of the surface states of the two ternary alloys after oxidation test (SEM/BSE examinations, SEM/EDS oxide determinations) 


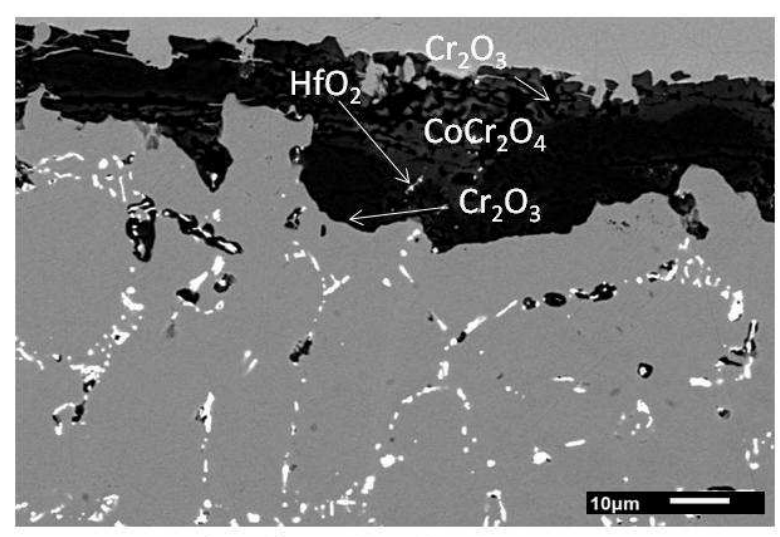

CoHfC- $1 / 1$ oxidized $50 \mathrm{~h}$ at $1200^{\circ} \mathrm{C}$

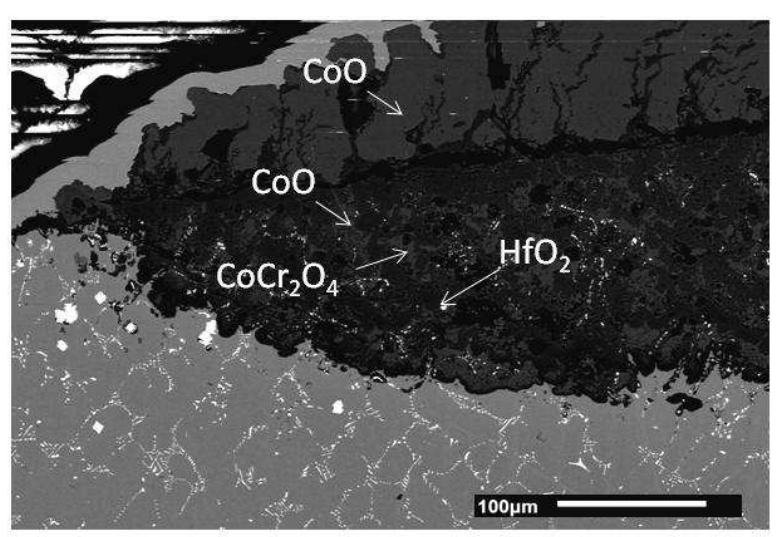

CoHfC-2/1 oxidized $50 \mathrm{~h}$ at $1200^{\circ} \mathrm{C}$

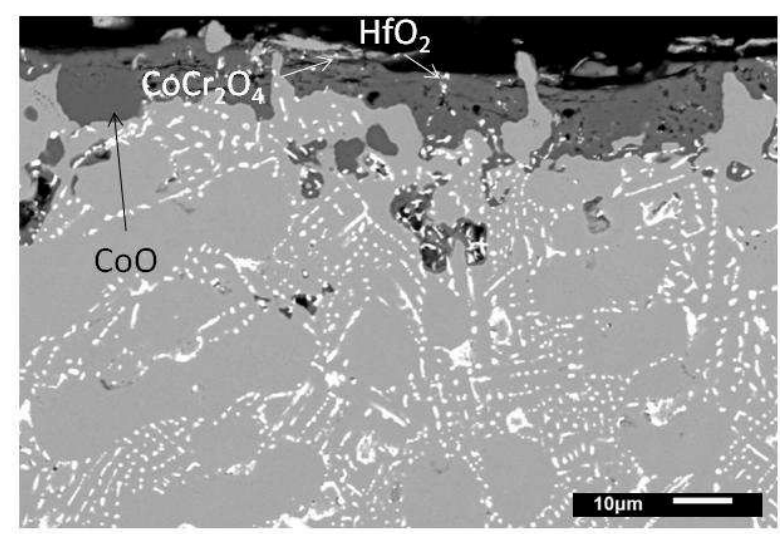

CoHfC- $2 / 2$ oxidized $50 \mathrm{~h}$ at $1200^{\circ} \mathrm{C}$

Fig. 14. Illustration of the surface states of the three HfC-reinforced alloys after oxidation test (SEM/BSE examinations, SEM/EDS oxide determinations) 

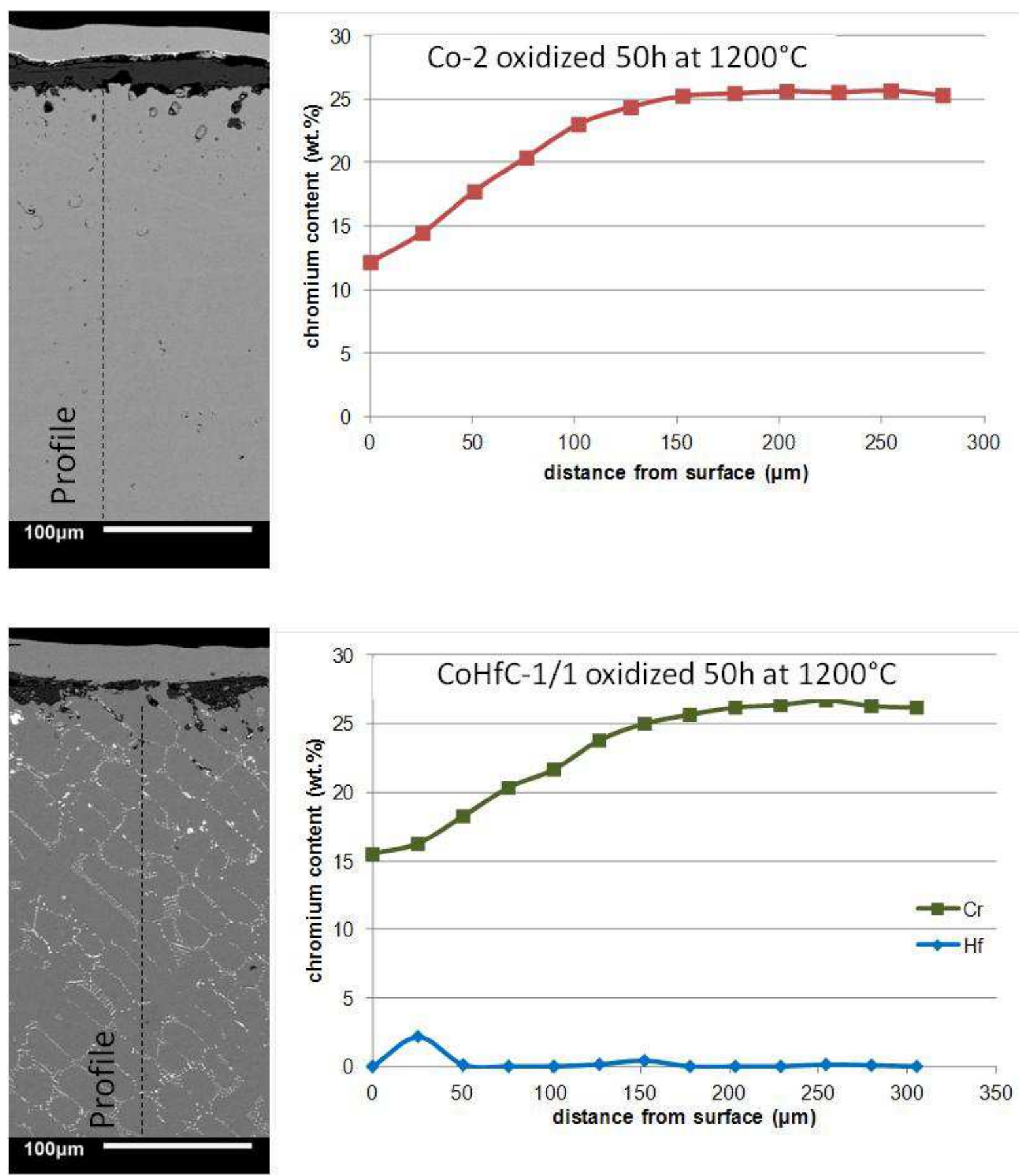

Fig. 15. Contents' profiles through the sub-surfaces affected by oxidation of one of the ternary alloys and of the low carbon $\mathrm{HfC}$-reinforced alloy 

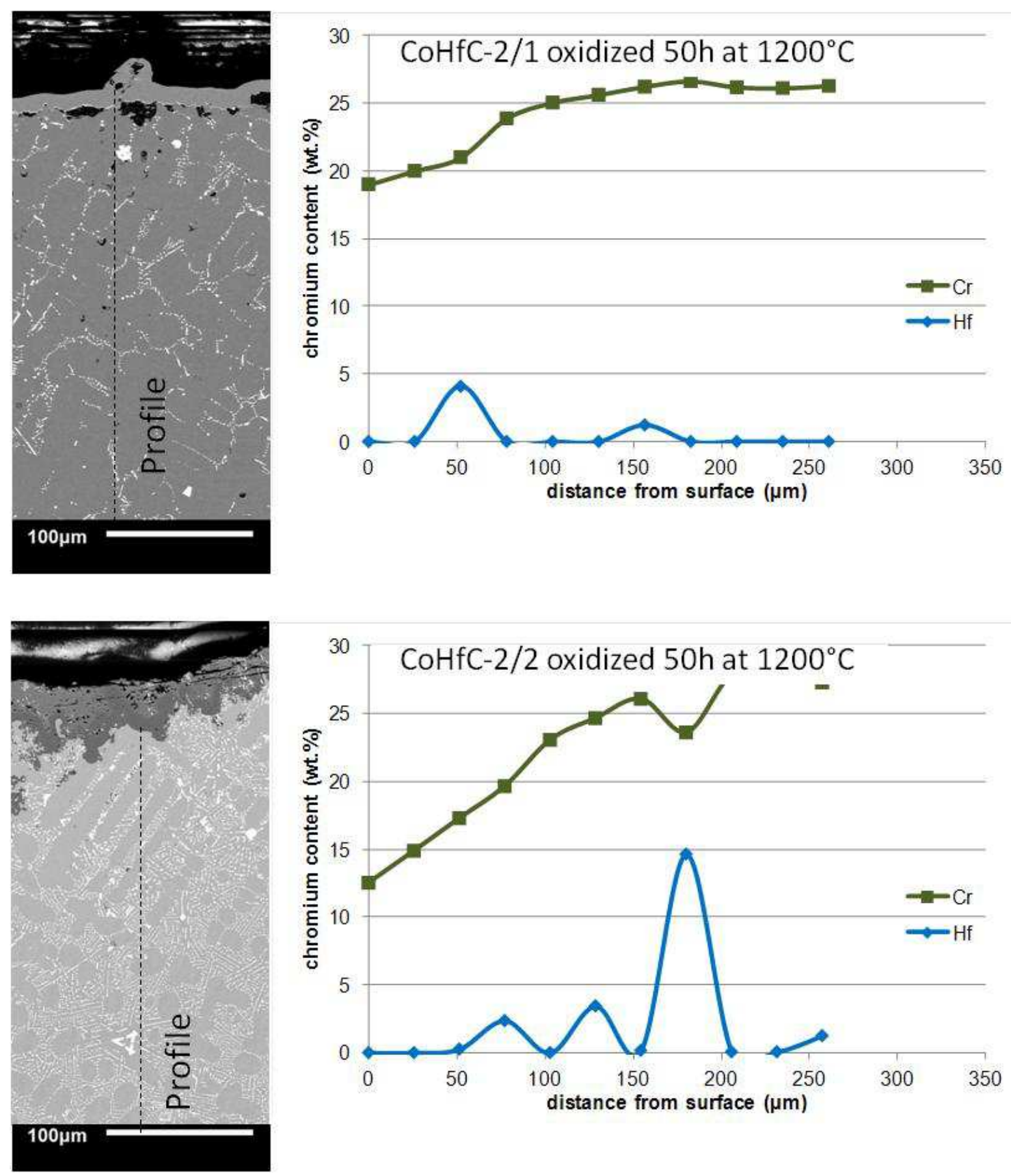

Fig. 16. Contents' profiles through the sub-surfaces affected by oxidation of the two high carbon HfC-reinforced alloys 